\title{
A versatile synthetic platform for polymer membrane libraries using functional networks
}

\author{
Joshua D. Moon ${ }^{1}$, Rahul Sujanani², Zhishuai Geng ${ }^{1}$, Benny D. Freeman², Rachel A. \\ Segalman ${ }^{1,3, *}$, Craig J. Hawker ${ }^{1,4, *}$
}

1: Materials Department, University of California, Santa Barbara, CA 93106, USA

2: John J. McKetta Jr. Department of Chemical Engineering, The University of Texas at Austin, Austin, TX 78712, USA

3: Department of Chemical Engineering, University of California, Santa Barbara, CA 93106, USA

4: Department of Chemistry and Biochemistry, University of California, Santa Barbara, CA, 93106, USA

*Co-corresponding authors

\section{Supporting information}

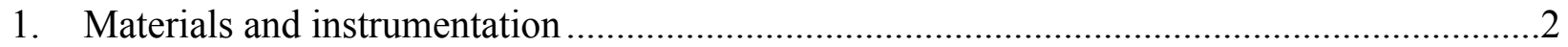

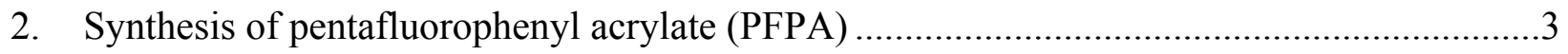

3. Free radical polymerization of PEGDA/PEGMEA/PFPA random copolymer networks ........3

4. Post-polymerization modification of PFPA networks with same monomer compositions......5

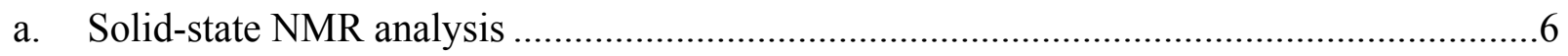

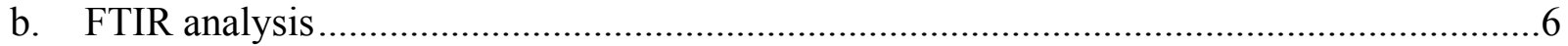

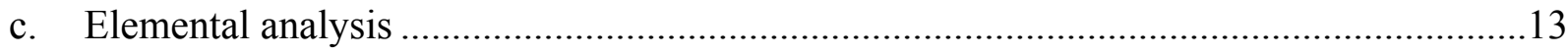

5. Characterization of byproduct from substitution reaction with 10 eq. 1-(3-

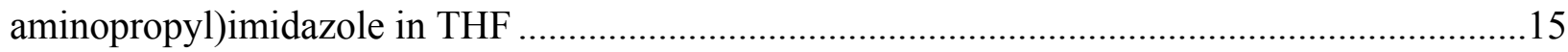

6. Post-polymerization modification of PFPA networks with same crosslinking density but

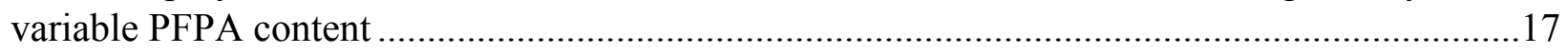

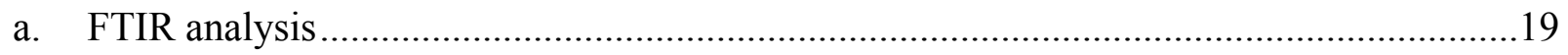

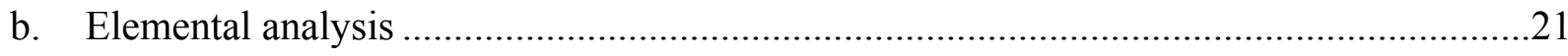

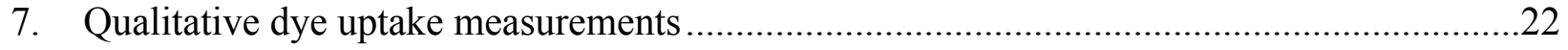




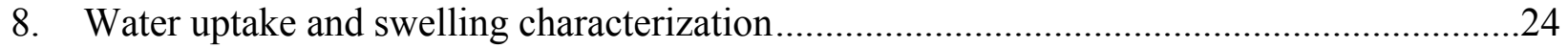

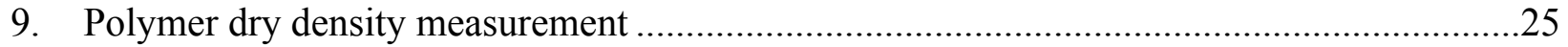

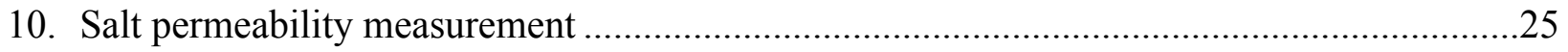

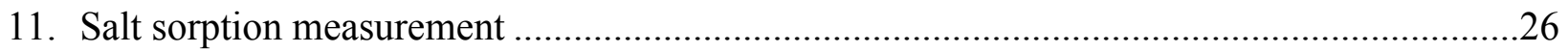

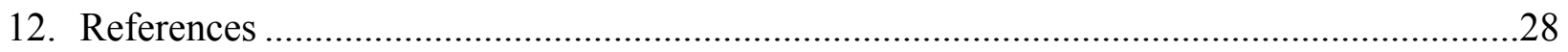

\section{Materials and instrumentation}

All chemicals were used as received unless otherwise noted. Acryloyl chloride ( $\geq 97 \%)$, polyethylene glycol diacrylate (PEGDA) $(\mathrm{Mn}=700$, contained inhibitor), polyethylene glycol methyl ether acrylate (PEGMEA) ( $\mathrm{Mn}=480$, contained inhibitor), 8M lithium chloride solution, hydrochloric acid (37\%), copper(II) chloride dihydrate ( $>99.0 \%$ and $>99.95 \%)$, iron(III) chloride hexahydrate (98.0-102.0\%), Bromophenol Blue (ACS reagent), Rhodamine B (95\%), Orange II sodium salt ( $\geq 85 \%)$, ), Fluorescein sodium salt (BioReagent grade), 4-(aminomethyl)piperidine (96\%), 1-(2-aminoethyl)piperidine (98\%), 1-(2-aminoethyl)pyrrolidine (98\%), 3-

(dimethylamino)-1-propylamine (99\%), N-methyldodecylamine (97\%), didodecylamine (97\%), isopropanol ( $\geq 99.5 \%)$, and $n$-heptane were purchased from Sigma Aldrich. Pentafluorophenol (PFP) (99+\%), triethylamine, tetrahydrofuran (THF), dichloromethane (DCM), sodium chloride $(>99 \%)$, tris(hydroxymethyl)aminomethane (ACS grade), and Bromothymol Blue sodium salt (reagent grade) were purchased from Fisher Scientific. $\quad \beta$-alanine $(98 \%)$, L-histidine ( $\geq 98 \%)$, glycine (99\%), L-valine (99\%), dodecylamine (97\%), and additional triethylamine were purchased from Alfa Aesar. 2,2-dimethoxy-2-phenylacetophenone (DMPA) (99\%), lithium chloride ( $>99 \%$ ), L-phenylalanine ( $\geq 98.5 \%)$, taurine $(99 \%)$, Thymol Blue (pure), and Methyl Orange (ACS reagent) were purchased from Acros. 1M magnesium chloride solution, cystamine dihydrochloride ( $\geq 98.0 \%$ ), and 5(6)-carboxyfluorescein ( $>95 \%)$ were purchased from Fluka. Zinc chloride (ACS reagent) was purchased from Supelco. 4-(2-aminoethyl)pyridine) ( $\geq 97.0 \%)$ was purchased from TCI. Tryptamine (99\%) was purchased from Chem-Impex International. 1(3-aminopropyl)imidazole (APIM) (98\%) was purchased from Alfa Aesar and purified by passing once through basic alumina.

FTIR-ATR analysis was performed at room temperature using a Thermo Nicolet iS10 spectrometer equipped with a diamond ATR accessory using 64 scans. Data were corrected using automatic baseline correction. ${ }^{1} \mathrm{H},{ }^{13} \mathrm{C}$, and ${ }^{19} \mathrm{~F}$ NMR spectra were recorded on a Varian VNMRS $600 \mathrm{MHz}$ spectrometer.

Solid-state NMR experiments were conducted using an $18.8 \mathrm{~T}$ Bruker $\left({ }^{1} \mathrm{H}-800 \mathrm{MHz},{ }^{19} \mathrm{~F}-\right.$ $752.98 \mathrm{MHz}{ }^{13} \mathrm{C}-517.98 \mathrm{MHz}$ ) solid-state NMR spectrometer and a $2.5 \mathrm{~mm}$ double resonance probe at magic angle spinning rate of $25 \mathrm{kHz} .{ }^{19} \mathrm{~F}$ signal was detected using a single $90^{\circ}$ pulse $(3.1 \mu \mathrm{s})$ with $8.5 \mathrm{~ms}$ acquisition time, 2208 scans ( 2 dummy scans per 16 scans), and a recycle delay of $3 \mathrm{~s}$ without ${ }^{1} \mathrm{H}$ decoupling. ${ }^{13} \mathrm{C}$ NMR signal was acquired using a single $3 \mu \mathrm{s} 90^{\circ}$ pulse with $10.2 \mathrm{~ms}$ acquisition time, 40,352 scans (2 dummy scans per 32 scans), and a recycle delay of $10 \mathrm{~s}$ with $54.35 \mathrm{MHz}{ }^{1} \mathrm{H}$ decoupling using Spinal64 during acquisition. ${ }^{1} \mathrm{H}$ magnetizations were detected using solid echo experiment: a 3.1- $\mu \mathrm{s} 90^{\circ}$ saturation pulse followed by a rotorsynchronized delay ( 20 rotor periods, $0.8 \mathrm{~ms}$ ). The signal was then refocused by a $6.2-\mu \mathrm{s} 180^{\circ}$ pulse. ${ }^{1} \mathrm{H}$ signal was collected using $10.2 \mathrm{~ms}$ acquisition time, 1 scan and a recycling delay of $3 \mathrm{~s}$. 


\section{Synthesis of pentafluorophenyl acrylate (PFPA)}
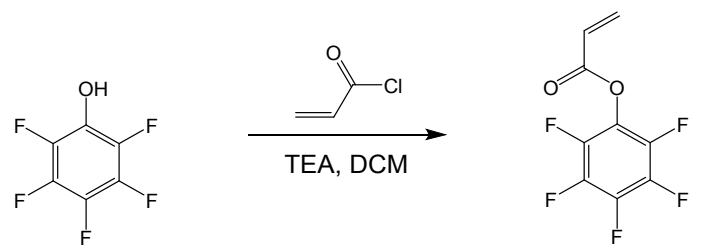

Scheme S1. Synthesis of pentafluorophenyl acrylate (PFPA).

In a roundbottom flask, pentafluorophenol (30 g, $0.16 \mathrm{~mol}), \mathrm{Et}_{3} \mathrm{~N}(24 \mathrm{~mL}, 0.17 \mathrm{~mol})$, and DCM $(300 \mathrm{~mL})$ were mixed and cooled to $0{ }^{\circ} \mathrm{C}$. Acryloyl chloride $(15 \mathrm{~mL}, 0.18 \mathrm{~mol})$ was added drop-wise, and the mixture was stirred and allowed to warm to room temperature overnight. The pale yellow product was obtained after washing the organic phase with $\mathrm{NaHCO}_{3}$ solution, dried over $\mathrm{MgSO}_{4}$, filtered, and concentrated under reduced pressure. The product was decolored after purification using a short silica gel column before use (34 g, 88\%), which was found to be necessary to yield films with high gel fractions. ${ }^{1} \mathrm{H}$ NMR $\left(600 \mathrm{MHz}\right.$, in $\left.\mathrm{CDCl}_{3}\right): \delta 6.69(\mathrm{~d}, J=$ $17.3 \mathrm{~Hz}, 1 \mathrm{H}), 6.35$ (dd, $J=17.3,10.6 \mathrm{~Hz}, 1 \mathrm{H}), 6.15(\mathrm{~d}, J=10.6 \mathrm{~Hz}, 1 \mathrm{H}) ;{ }^{13} \mathrm{C} \mathrm{NMR}(150 \mathrm{MHz}$, $\left.\mathrm{CDCl}_{3}\right): \delta 161.8,142.3,140.6,138.9,137.2,135.3,134.3,127.6,125.4 ;{ }^{19} \mathrm{~F} \mathrm{NMR}(565 \mathrm{MHz}$, in $\left.\mathrm{CDCl}_{3}\right): \delta-153.4(\mathrm{~d}, 2 \mathrm{~F}),-159.0(\mathrm{t}, 1 \mathrm{~F}),-163.3(\mathrm{t}, 2 \mathrm{~F})$; FTIR $\left(v, \mathrm{~cm}^{-1}\right): 1770(\mathrm{C}=\mathrm{O})$. Chemical shifts $(\delta)$ are reported in ppm relative to residual chloroform in $\mathrm{CDCl}_{3}(7.26 \mathrm{ppm})$.

\section{Free radical polymerization of PEGDA/PEGMEA/PFPA random copolymer networks}

PEGDA(Mw=700), PEGMEA(Mw=480), PFPA, and $0.1 \mathrm{wt} \%$ DMPA photoinitiator were added in the desired ratios to glass vials covered with aluminum foil and mixed vigorously for 30 seconds or until DMPA was fully dissolved. The monomer mixtures were sonicated for one to two minutes to remove air bubbles. The mixtures were sandwiched between two quartz plates with $400 \mu \mathrm{m}$ metal feeler gauges acting as spacers to control film thickness. The films was irradiated using a $365 \mathrm{~nm}$ UV bench lamp for 90 seconds at an approximate power density of $2 \mathrm{~mW} / \mathrm{cm}^{2}$ (cf., Scheme 1). Crosslinked PEGDA/PEGMEA/PFPA random copolymer films were $\sim 5 \mathrm{~cm}$ in diameter and $\sim 400 \mu \mathrm{m}$ thick.

Unsubstituted 21/0/79 mol\% PEGDA/PEGMEA/PFPA random copolymer network: solid-state ${ }^{1} \mathrm{H}$ NMR (800 MHz): $\delta 3.3$ (s); solid-state ${ }^{13} \mathrm{C}$ NMR $(517.98 \mathrm{MHz}): \delta 169.7,138.4$, 124.0, 69.7, 41.4; solid-state ${ }^{19} \mathrm{~F}$ NMR (752.98 MHz): $\delta-168(\mathrm{~m})$. Refer to Figures S1, S2, and $\mathrm{S} 3$ for solid-state NMR plots. ${ }^{13} \mathrm{C}$ spectra are shifted so the PEG peak is at $70 \mathrm{ppm}$. 


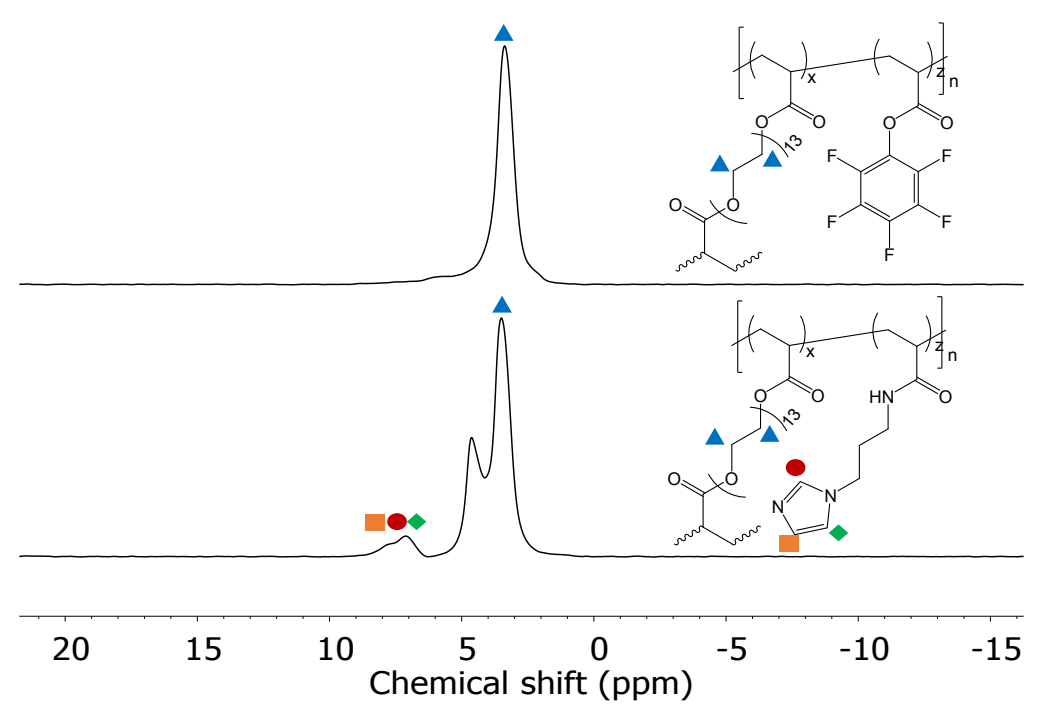

Figure S1. Solid-state ${ }^{1}$ H NMR for (top) unsubstituted 21/0/79 mol\% PEGDA/PEGMEA/PFPA random copolymer network and (bottom) same polymer composition after reaction with 10 eq. 1(3-aminopropyl)imidazole in THF.

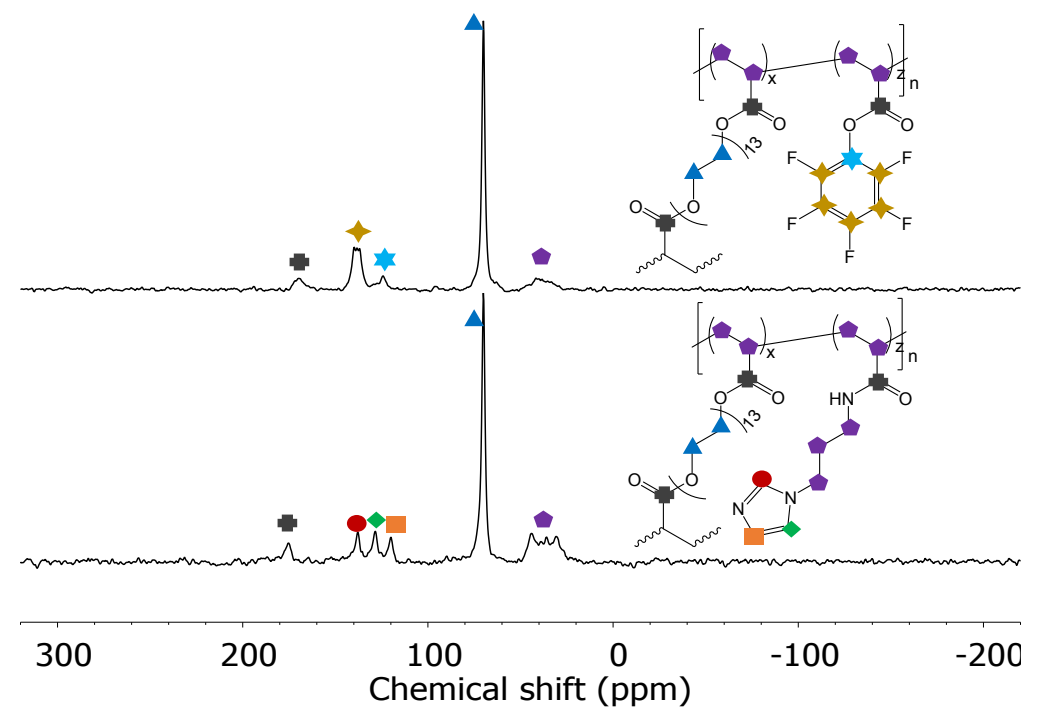

Figure S2. Solid-state ${ }^{13} \mathrm{C}$ NMR for (top) unsubstituted 21/0/79 mol\% PEGDA/PEGMEA/PFPA random copolymer network and (bottom) same polymer composition after reaction with 10 eq. 1(3-aminopropyl)imidazole in THF. Spectra are shifted so the PEG peak is at $70 \mathrm{ppm}$. 


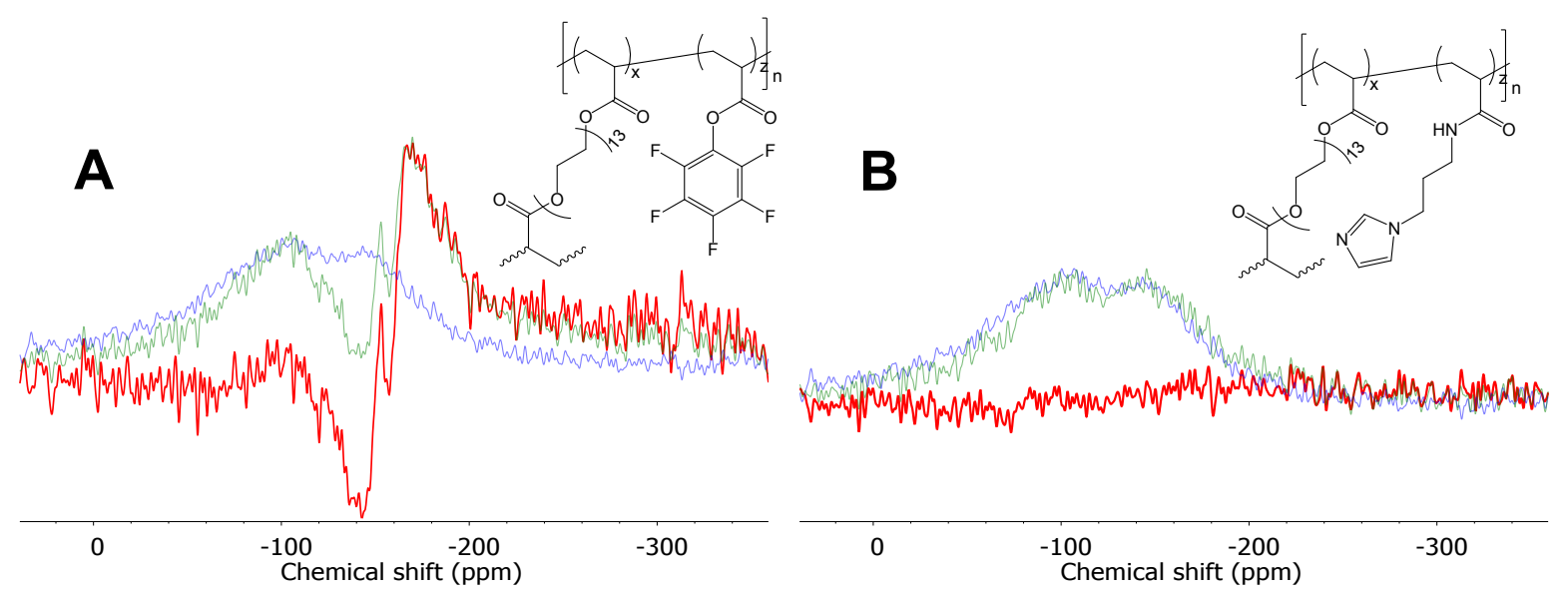

Figure S3. Solid-state ${ }^{19}$ F NMR for (A) unsubstituted 21/0/79 mol\% PEGDA/PEGMEA/PFPA random copolymer network and (B) same polymer composition after reaction with 10 eq. 1-(3aminopropyl)imidazole in THF. Blue traces are the probe backgrounds, green traces are the samples, and red traces are the samples after background subtraction.

\section{Post-polymerization modification of PFPA networks with same monomer compositions}

$2 \mathrm{wt} \%$ solutions containing 5 equivalents (relative to PFPA) of 1-(2aminoethyl)pyrrolidine, 1-(2-aminoethyl)piperidine, 4-(aminomethyl)piperidine, 4-(2aminoethyl)pyridine, dodecylamine, 3-(dimethylamino)-1-propylamine, tryptamine, $\mathrm{N}$ methyldodecylamine, or didodecylamine in THF were prepared. A $5 \mathrm{wt} \%$ solution containing 10 eq. 1-(3-aminopropyl)imidazole in THF was prepared. A $1.2 \mathrm{wt} \%$ aqueous solution of 5 eq. 1(3-aminopropyl)imidazole was prepared. 5 eq. 1,3-diamino-2-hydroxypropane-N,N,N',N'tetraacetic acid was dissolved in water to prepare a $\sim 2 \mathrm{wt} \%$ solution, to which 25 eq. of triethylamine were added to deprotonate the acetic acid groups and promote dissolution. 2\% aqueous solutions of 10 eq. glycine, $\beta$-alanine, taurine, phenylalanine, or L-valine were prepared, to which were added 15 eq. of triethylamine. A $2 \%$ aqueous solution of 5 eq. L-histidine was prepared, to which was added 12 eq. triethylamine. A 2\% aqueous solution of 10 eq. tris(hydroxymethyl)aminomethane (tris base) was prepared without triethylamine. A 2\% aqueous solution of 2.5 eq. cystamine dihydrochloride was prepared, to which was added 6 eq. triethylamine. A $2 \%$ aqueous solution of 5 eq. dopamine hydrochloride was prepared, to which was added 7.5 eq. triethylamine. Finally, as a control, a 2\% aqueous triethylamine solution (7.5 eq.) was prepared with no reactive amine. 150-300 mg samples of PEGDA/PEGMEA/PFPA random copolymer networks containing 28 mol\% PEGDA, $20 \mathrm{~mol} \%$ PEGMEA, and $52 \mathrm{~mol} \%$ PFPA were cut and immersed in reaction solutions for 24 hours at room temperature. After substitution, films remained clear with the exception of the dopamine-functionalized sample, which turned yellowish-brown.

Polymer samples were removed from reaction mixtures and soaked in excess $0.1 \mathrm{M}$ aqueous $\mathrm{HCl}$ for 24 hours to dissolve any residual byproducts. Samples were then soaked in deionized water for a few days, which was exchanged multiple times. Finally, samples were dried at $50{ }^{\circ} \mathrm{C}$ under full vacuum overnight before FTIR analysis and dried at $50{ }^{\circ} \mathrm{C}$ for 12 hours prior to elemental analysis. 
Two $1 \mathrm{~g}$ samples of 21/0/79 mol\% PEGDA/PEGMEA/PFPA were prepared via freeradical polymerization as discussed above. One sample was immersed in a $5 \mathrm{wt} \%$ solution containing 10 eq. 1-(3-aminopropyl)imidazole in THF for 24 hours at room temperature. The product was then soaked in excess $0.1 \mathrm{M} \mathrm{HCl}$ for 24 hours, then $0.1 \mathrm{M}$ triethylamine for 24 hours, then finally in deionized water for several days before vacuum drying at room temperature for 36 hours. The other sample was kept in THF without amine for several days, then vacuum dried at room temperature for 36 hours. Solid-state NMR spectra were recorded for both samples (cf., Figures S1-S3).

\section{a. Solid-state NMR analysis}

21/0/79 mol\% PEGDA/PEGMEA/PFPA random copolymer network after reaction with 1-(3-aminopropyl)imidazole in THF: solid-state ${ }^{1} \mathrm{H}$ NMR $(800 \mathrm{MHz}): \delta 7.1(\mathrm{~m}), 3.5$ (s); solidstate ${ }^{13} \mathrm{C}$ NMR $(517.98 \mathrm{MHz}): \delta 175.3,137.8,128.5,119.9,70.2,35.9$; solid-state ${ }^{19} \mathrm{~F}$ NMR $(752.98 \mathrm{MHz})$ : no peaks detected. Refer to Figures S1, S2, and S3 for solid-state NMR spectra. ${ }^{1} \mathrm{H}$ NMR peak at $\delta 4.61$ is likely residual solvent. ${ }^{13} \mathrm{C}$ spectra are shifted so the PEG peak is at $70 \mathrm{ppm}$.

\section{b. FTIR analysis}

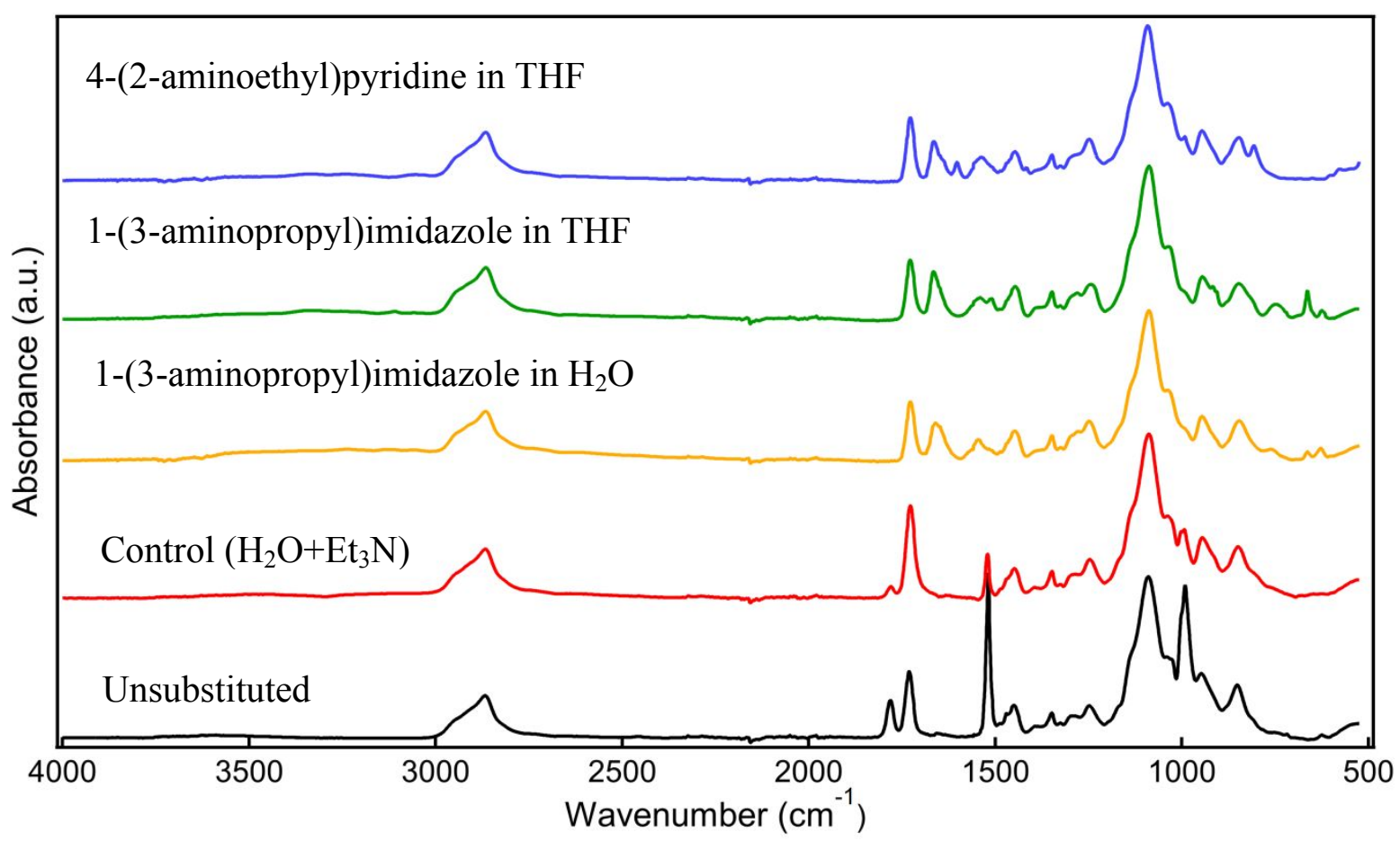

Figure S4. FTIR-ATR spectrograms of substituted and unsubstituted 28/20/52 mol\% PEGDA/PEGMEA/PFPA random copolymer networks. From top to bottom: product after reaction with 4-(2-aminoethyl)pyridine in THF; product after reaction with 1-(3aminopropyl)imidazole in THF; product after reaction with 1-(3-aminopropyl)imidazole in $\mathrm{H}_{2} \mathrm{O}$; product after control reaction in aqueous triethylamine; unsubstituted network (no reaction). 


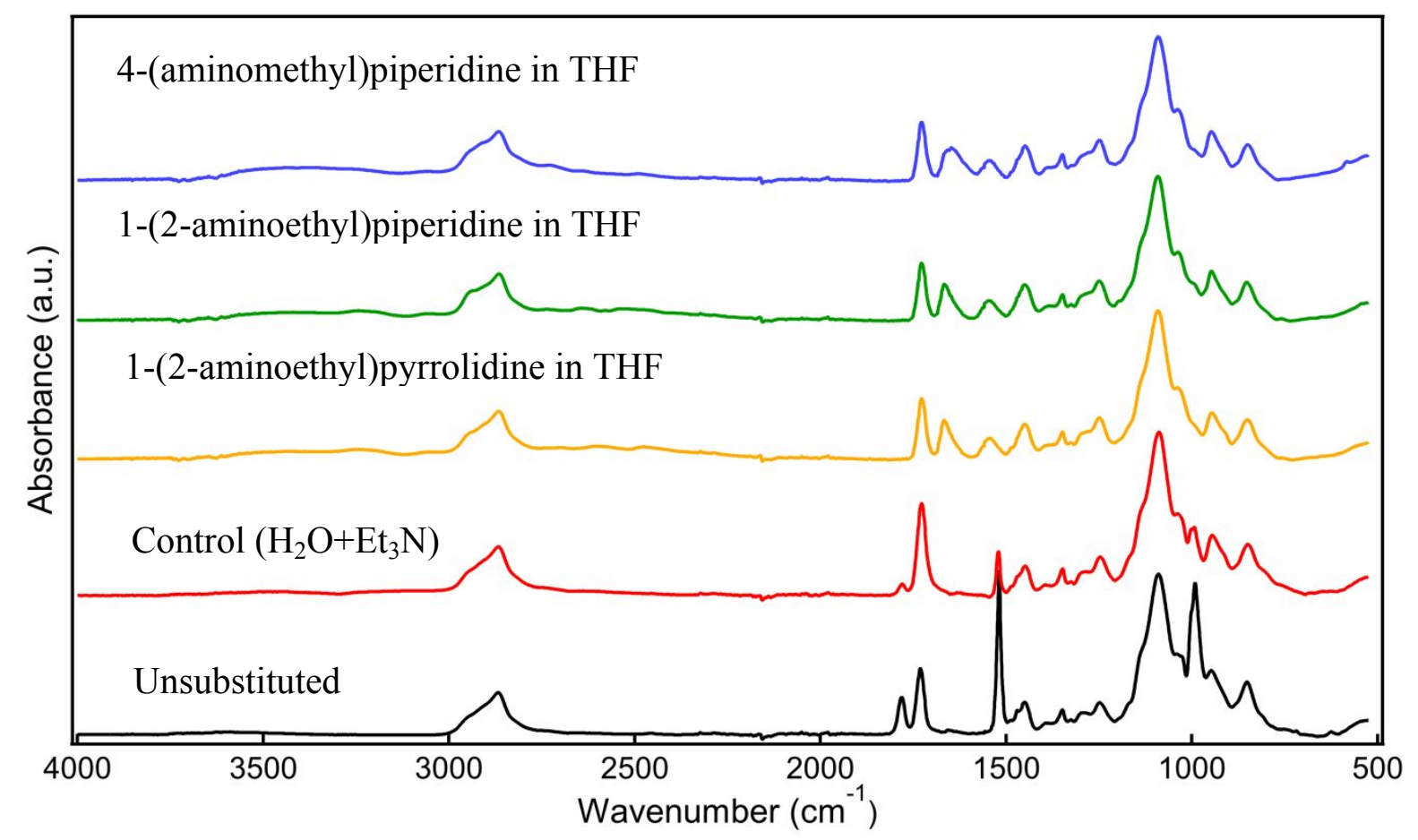

Figure S5. FTIR-ATR spectrograms of substituted and unsubstituted 28/20/52 mol\% PEGDA/PEGMEA/PFPA random copolymer networks. From top to bottom: product after reaction with 4-(aminomethyl)piperidine in THF; product after reaction with 1-(2aminoethyl)piperidine in THF; product after reaction with 1-(2-aminoethyl)pyrrolidine in THF; product after control reaction in aqueous triethylamine; unsubstituted network (no reaction).

Control reaction (aqueous triethylamine) resulted in partial hydrolysis of the PFPA, indicated by weakening of PFPA stretching bands at $1780 \mathrm{~cm}^{-1}(\mathrm{C}=\mathrm{O}), 1520 \mathrm{~cm}^{-1}(\mathrm{C}=\mathrm{C})$, and $985 \mathrm{~cm}^{-1}$ (C-F). Reactions with 1-(3-aminopropyl)imidazole in water and THF both resulted in complete loss of the three PFPA peaks and formation of amide peaks at $1660 \mathrm{~cm}^{-1}(\mathrm{C}=\mathrm{O})$, the latter of which was slightly weaker for the aqueous reaction. Reactions with 1-(2aminoethyl)pyrrolidine, 1-(2-aminoethyl)piperidine, 4-(aminomethyl)piperidine, and 4-(2aminoethyl)pyridine in THF also resulted in complete PFPA substitution and formation of amide peaks at $1660 \mathrm{~cm}^{-1}$. Additional peaks appeared at 1600 and $805 \mathrm{~cm}^{-1}$ after reaction with 1-(2aminoethyl)piperidine. 


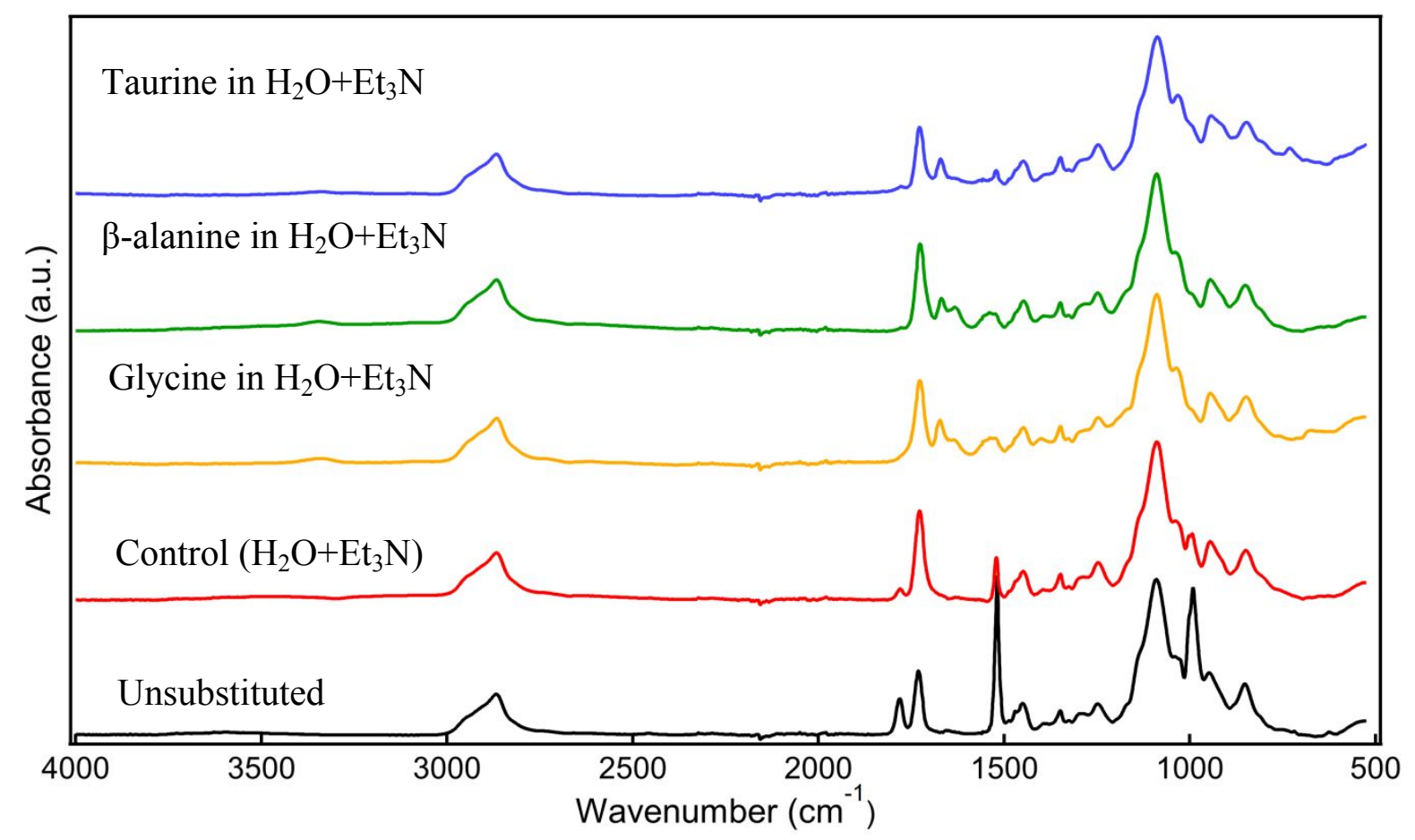

Figure S6. FTIR-ATR spectrograms of substituted and unsubstituted 28/20/52 mol\% PEGDA/PEGMEA/PFPA random copolymer networks. From top to bottom: product after reaction with taurine in water and triethylamine; product after reaction with $\beta$-alanine in water and triethylamine; product after reaction with glycine in water and triethylamine; product after control reaction in aqueous triethylamine; unsubstituted network (no reaction). 


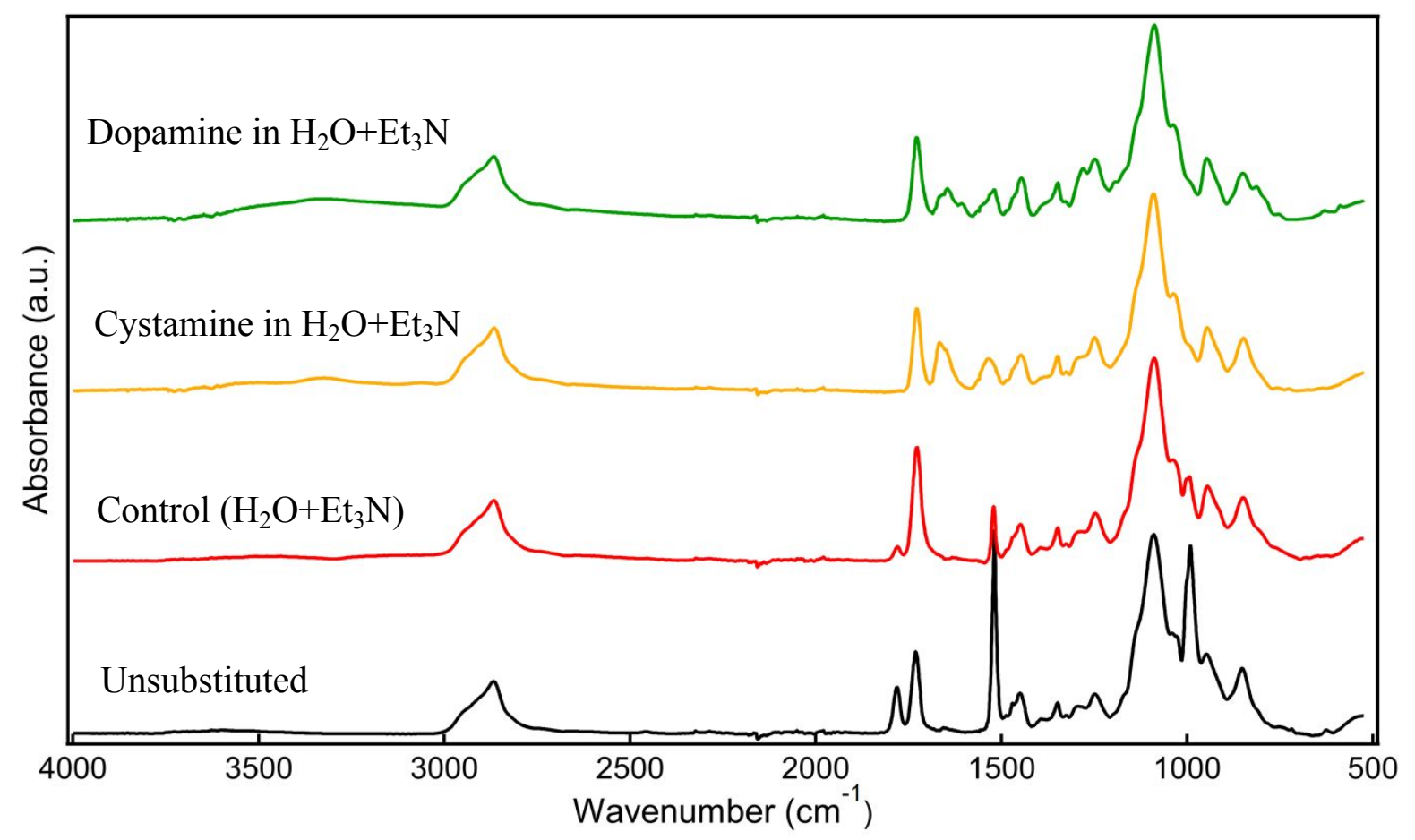

Figure S7. FTIR-ATR spectrograms of substituted and unsubstituted 28/20/52 mol\% PEGDA/PEGMEA/PFPA random copolymer networks. From top to bottom: product after reaction with dopamine hydrochloride in water and triethylamine; product after reaction with cystamine dihydrochloride in water and triethylamine; product after control reaction in aqueous triethylamine; unsubstituted network (no reaction).

Reactions with glycine, $\beta$-alanine, cystamine, and dopamine resulted in complete PFPA substitution and formation of amide peaks around $1660-1670 \mathrm{~cm}^{-1}$. The product from reaction with dopamine exhibited additional peaks at $1600,810,630$, and $590 \mathrm{~cm}^{-1}$. Reaction with taurine resulted in partial PFPA substitution, with very weak peaks remaining at 1780 and 1520 $\mathrm{cm}^{-1}$. 


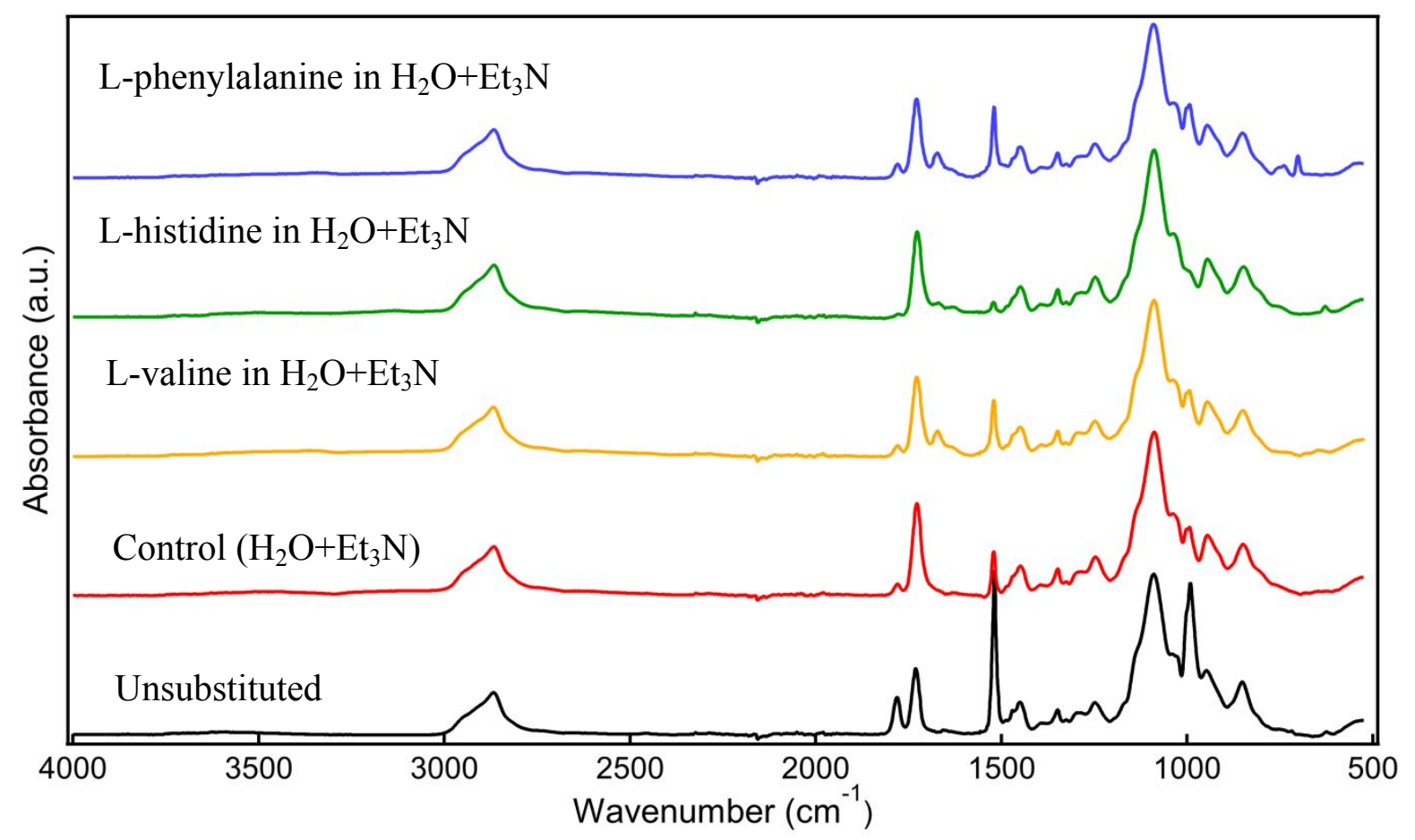

Figure S8. FTIR-ATR spectrograms of substituted and unsubstituted 28/20/52 mol\% PEGDA/PEGMEA/PFPA random copolymer networks. From top to bottom: product after reaction with L-phenylalanine in water and triethylamine; product after reaction with L-histidine in water and triethylamine; product after reaction with L-valine in water and triethylamine; product after control reaction in aqueous triethylamine; unsubstituted network (no reaction).

Reactions with L-phenylalanine, L-histidine, and L-valine resulted in partial substitution of PFPA, with significant PFPA peaks remaining at 1780, 1520, and $985 \mathrm{~cm}^{-1}$ for Lphenylalanine and L-valine and small peaks remaining at 1780 and $1520 \mathrm{~cm}^{-1}$ for L-histidine. Formation of amide peaks around $1670 \mathrm{~cm}^{-1}$ were observed for all three products, albeit the amide peak for the L-histidine reaction was weak. Additional peaks appeared at 740 and 700 $\mathrm{cm}^{-1}$ after reaction with L-phenylalanine. 


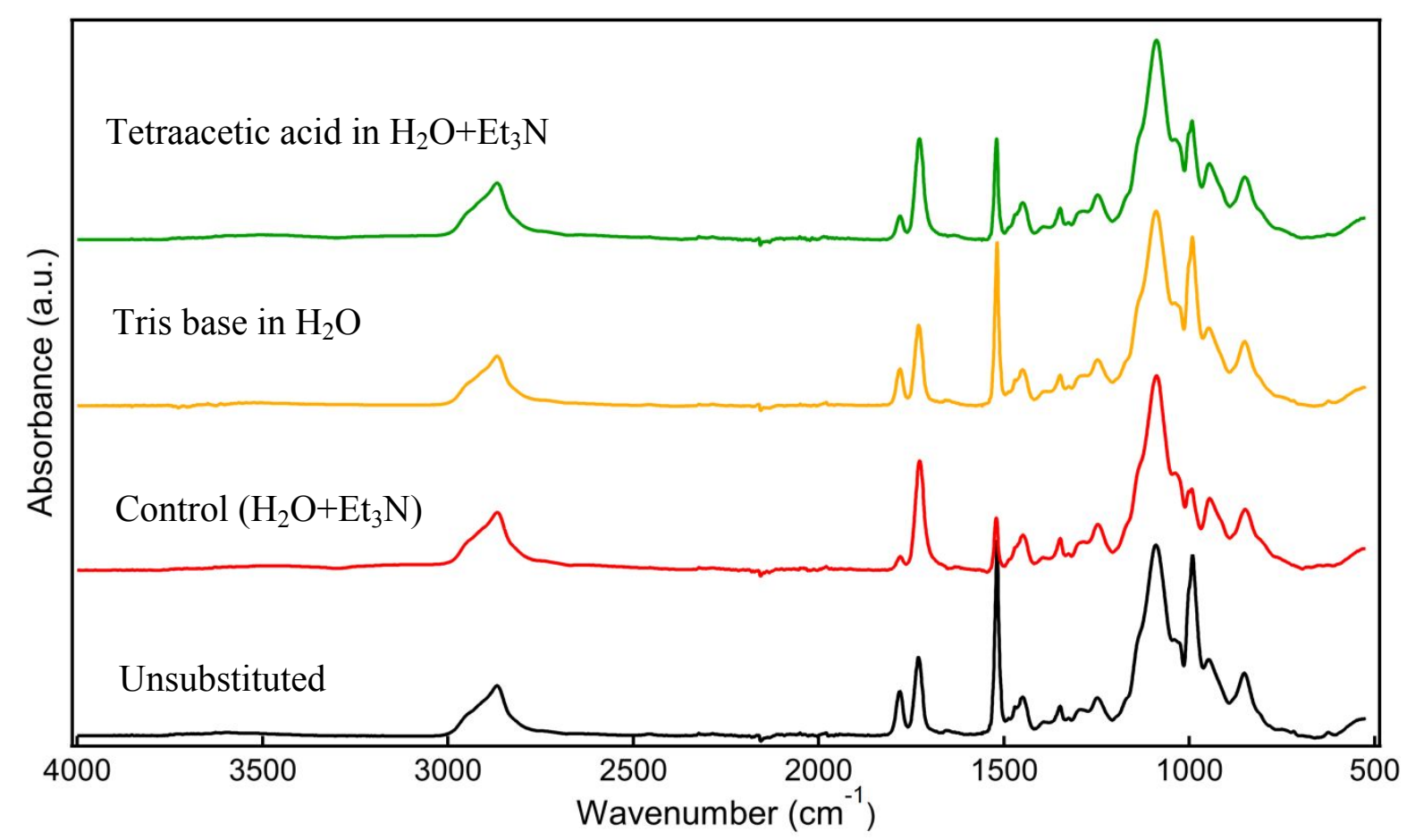

Figure S9. FTIR-ATR spectrograms of substituted and unsubstituted 28/20/52 mol\% PEGDA/PEGMEA/PFPA random copolymer networks. From top to bottom: product after reaction with 1,3-diamino-2-hydroxypropane-N,N,N',N'-tetraacetic acid in water and triethylamine; product after reaction with tris(hydroxymethyl)aminomethane in water; product after control reaction in aqueous triethylamine; unsubstituted network (no reaction).

Reactions with the tetraacetic acid and tris base were unsuccessful, as significant PFPA peaks remained after reaction, and no formation of new ester or amide peaks was observed. 


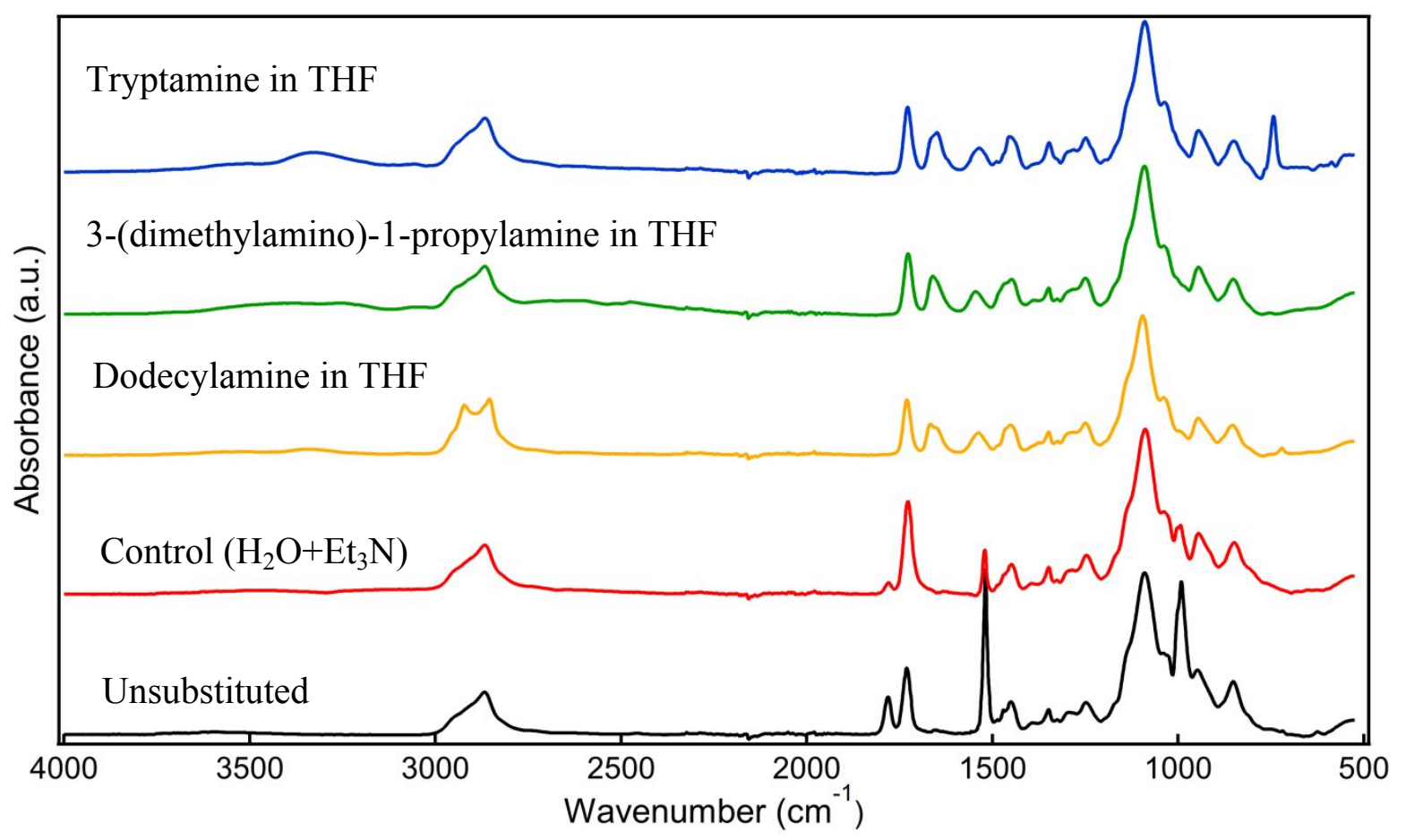

Figure S10. FTIR-ATR spectrograms of substituted and unsubstituted 28/20/52 mol\% PEGDA/PEGMEA/PFPA random copolymer networks. From top to bottom: product after reaction with tryptamine in THF; product after reaction with 3-(dimethylamino)-1-propylamine in THF; product after reaction with dodecylamine in THF; product after control reaction in aqueous triethylamine; unsubstituted network (no reaction). 


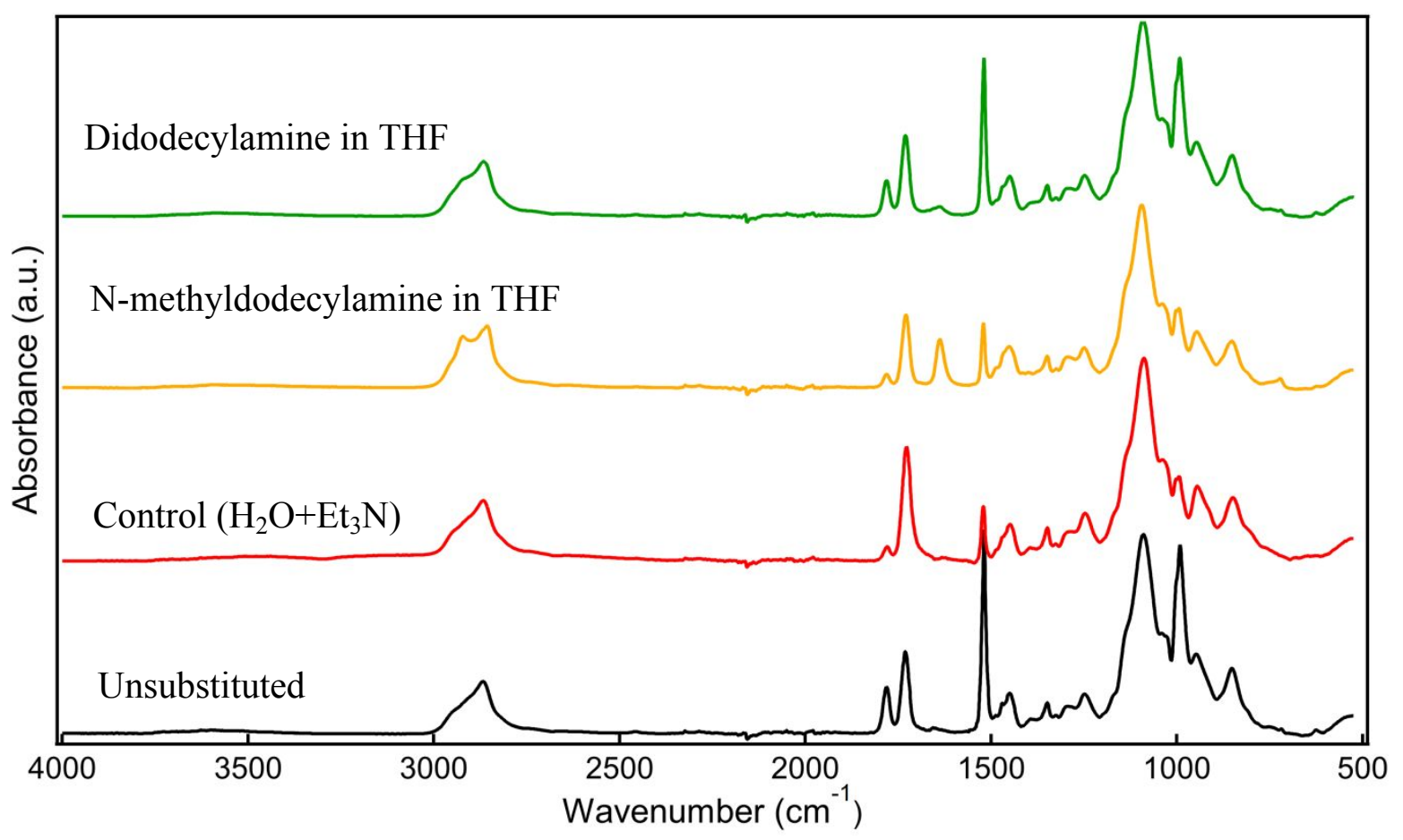

Figure S11. FTIR-ATR spectrograms of substituted and unsubstituted 28/20/52 mol\% PEGDA/PEGMEA/PFPA random copolymer networks. From top to bottom: product after reaction with didodecylamine in THF; product after reaction with $\mathrm{N}$-methyldodecylamine in THF; product after control reaction in aqueous triethylamine; unsubstituted network (no reaction).

Reactions with tryptamine, 3-(dimethylamino)-1-propylamine, and dodecylamine in THF resulted in complete PFPA substitution and formation of amide peaks around 1660-1670 $\mathrm{cm}^{-1}$. The product from reaction with dodecylamine showed additional C-H stretching bands around $2925 \mathrm{~cm}^{-1}$. N-methyldodecylamine was less reactive than dodecylamine, as signals corresponding to PFPA $\mathrm{C}=\mathrm{O}, \mathrm{C}=\mathrm{C}$, and $\mathrm{C}-\mathrm{F}$ stretches were still present. Essentially no reaction was observed with didodecylamine, as the PFPA stretches were relatively unchanged after reaction and only a very weak amide peak formed.

\section{c. Elemental analysis}

Elemental analysis was performed by Midwest Microlabs (Indianapolis, IN). Samples were dried 12 hours at $50{ }^{\circ} \mathrm{C}$ prior to measurement. The analytical lab provided an estimated uncertainty of $\pm 0.4 \mathrm{wt} \%$ for each element. For some samples, the total mass of all the elements did not sum to $100 \%$ but rather ranged from 86 to $98 \%$. Some of this mass may be accounted for as residual chlorine in the samples from any $\mathrm{HCl}$ that was not removed during water washing. 
Table S1. Theoretical and actual elemental mass percentages determined by elemental analysis for unsubstituted and substituted 28/20/52 mol\% PEGDA/PEGMEA/PFPA random copolymer networks. Oxygen analysis could not be performed for fluorinecontaining samples due to interference with fluorine.

\begin{tabular}{|c|c|c|c|c|c|c|c|c|c|c|c|c|c|}
\hline & & Theo & etical & $\operatorname{ass} \%$ & & & & Actu & mas & & & & \\
\hline Reagent & Solvent & $\mathbf{C}$ & $\mathbf{H}$ & $\mathbf{N}$ & $\mathbf{O}$ & $\mathbf{F}$ & $\mathbf{S}$ & $\mathbf{C}$ & $\mathbf{H}$ & $\mathbf{N}$ & $\mathbf{O}$ & $\mathbf{F}$ & $\mathbf{S}$ \\
\hline Unsubstituted & None & 52.1 & 6.4 & 0.0 & 29.7 & 11.9 & - & 51.4 & 6.4 & 0.0 & $\mathrm{~N} / \mathrm{A}$ & 8.6 & - \\
\hline 1-(3-aminopropyl)imidazole & THF & 56.2 & 8.2 & 5.7 & 29.9 & 0.0 & - & 55.7 & 7.6 & 5.5 & 30.4 & 0.2 & - \\
\hline 1-(3-aminopropyl)imidazole & $\mathrm{H}_{2} \mathrm{O}$ & 56.2 & 8.2 & 5.7 & 29.9 & 0.0 & - & 54.1 & 8.3 & 4.6 & $\mathrm{~N} / \mathrm{A}$ & 0.6 & - \\
\hline 4-(2-aminoethyl)pyridine & THF & 58.1 & 8.1 & 3.8 & 30.0 & 0.0 & - & 57.3 & 8.4 & 3.8 & 28.1 & 0.1 & - \\
\hline 1-(2-aminoethyl)pyrrolidine & THF & 57.1 & 8.8 & 3.9 & 30.3 & 0.0 & - & 53.8 & 8.5 & 3.6 & 20.1 & 0.1 & - \\
\hline 1-(2-aminoethyl)piperidine & THF & 57.6 & 8.9 & 3.8 & 29.7 & 0.0 & - & 54.8 & 8.7 & 3.4 & 23.9 & 0.1 & - \\
\hline 4-(aminomethyl)piperidine & THF & 57.1 & 8.8 & 3.9 & 30.3 & 0.0 & - & 54.3 & 8.6 & 3.3 & 25.1 & 0.1 & - \\
\hline glycine & $\mathrm{H}_{2} \mathrm{O}+\mathrm{Et}_{3} \mathrm{~N}$ & 53.3 & 7.9 & 2.0 & 36.7 & 0.0 & - & 53.4 & 7.5 & 1.8 & 29.9 & 0.3 & - \\
\hline$\beta$-alanine & $\mathrm{H}_{2} \mathrm{O}+\mathrm{Et}_{3} \mathrm{~N}$ & 54.0 & 8.1 & 2.0 & 36.0 & 0.0 & - & 53.7 & 8.1 & 1.6 & 26.6 & 0.3 & - \\
\hline taurine & $\mathrm{H}_{2} \mathrm{O}+\mathrm{Et}_{3} \mathrm{~N}$ & 49.7 & 7.7 & 1.9 & 36.4 & 0.0 & 4.3 & 50.9 & 7.9 & 1.3 & $\mathrm{~N} / \mathrm{A}$ & 0.8 & 2.6 \\
\hline cystamine & $\mathrm{H}_{2} \mathrm{O}+\mathrm{Et}_{3} \mathrm{~N}$ & 51.1 & 8.1 & 3.7 & 28.8 & 0.0 & 8.4 & 52.6 & 7.9 & 2.5 & 21.1 & 0.2 & 5.2 \\
\hline dopamine & $\mathrm{H}_{2} \mathrm{O}+\mathrm{Et}_{3} \mathrm{~N}$ & 57.3 & 7.9 & 1.8 & 32.9 & 0.0 & - & 56.7 & 8.1 & 1.4 & 20.0 & 0.0 & - \\
\hline L-valine & $\mathrm{H}_{2} \mathrm{O}+\mathrm{Et}_{3} \mathrm{~N}$ & 55.2 & 8.3 & 1.9 & 34.6 & 0.0 & - & 54.4 & 7.9 & 1.1 & $\mathrm{~N} / \mathrm{A}$ & 1.7 & - \\
\hline L-histidine & $\mathrm{H}_{2} \mathrm{O}+\mathrm{Et}_{3} \mathrm{~N}$ & 54.0 & 7.6 & 5.5 & 32.9 & 0.0 & - & 54.0 & 8.1 & 1.5 & $\mathrm{~N} / \mathrm{A}$ & 0.6 & - \\
\hline L-phenylalanine & $\mathrm{H}_{2} \mathrm{O}+\mathrm{Et}_{3} \mathrm{~N}$ & 58.0 & 7.8 & 1.8 & 32.4 & 0.0 & - & 54.9 & 7.5 & 0.9 & $\mathrm{~N} / \mathrm{A}$ & 2.9 & - \\
\hline $\begin{array}{l}\text { tris(hydroxymethyl)amino } \\
\text { methane }\end{array}$ & $\mathrm{H}_{2} \mathrm{O}$ & 53.3 & 8.3 & 1.9 & 36.6 & 0.0 & - & 52.4 & 6.7 & 0.1 & N/A & 6.5 & - \\
\hline $\begin{array}{l}\text { 1,3-diamino-2- } \\
\text { hydroxypropane-N,N,N',N'- } \\
\text { tetraacetic acid }\end{array}$ & $\mathrm{H}_{2} \mathrm{O}+\mathrm{Et}_{3} \mathrm{~N}$ & 50.8 & 7.2 & 3.0 & 39.0 & 0.0 & - & 53.2 & 6.9 & 0.1 & N/A & 3.8 & - \\
\hline Control (no amine/alcohol) & $\mathrm{H}_{2} \mathrm{O}+\mathrm{Et}_{3} \mathrm{~N}$ & - & - & - & - & - & - & 53.8 & 8.0 & 0.2 & $\mathrm{~N} / \mathrm{A}$ & 1.9 & - \\
\hline
\end{tabular}




\section{Characterization of byproduct from substitution reaction with 10 eq. 1-(3- aminopropyl)imidazole in THF}

Small white crystals were observed to form during reaction with 10 eq. 1-(3aminopropyl)imidazole in THF (cf., Figure S12). Single crystal analysis revealed the triclinic crystals were composed of a salt formed by proton transfer from pentafluorophenol that eluted from the polymer network after substitution to excess 1-(3-aminopropyl)imidazole in solution. Crystalline byproduct: ${ }^{1} \mathrm{H}$ NMR $\left(600 \mathrm{MHz}\right.$, in $\left.\mathrm{D}_{2} \mathrm{O}\right): \delta 7.73(\mathrm{~s}, 1 \mathrm{H}), 7.20(\mathrm{~s}, 1 \mathrm{H}), 7.06(\mathrm{~s}, 1 \mathrm{H})$, 4.17 (t, $2 \mathrm{H}), 2.97$ (m, $2 \mathrm{H}), 2.18$ (p, $2 \mathrm{H}) ;{ }^{13} \mathrm{C}$ NMR (151 MHz, in $\left.\mathrm{D}_{2} \mathrm{O}\right): \delta$ 141.5, 139.9, 138.9, $137.8,137.3,127.9,119.9,43.8,36.7,28.2 ;{ }^{19} \mathrm{~F}$ NMR (564 MHz, in $\left.\mathrm{D}_{2} \mathrm{O}\right): \delta-168.1$ (m, $\left.2 \mathrm{~F}\right)$, -169.5 (m, 2 F), -182.8 (m, 1 F). Refer to Figures S13-S16 for solution NMR plots.
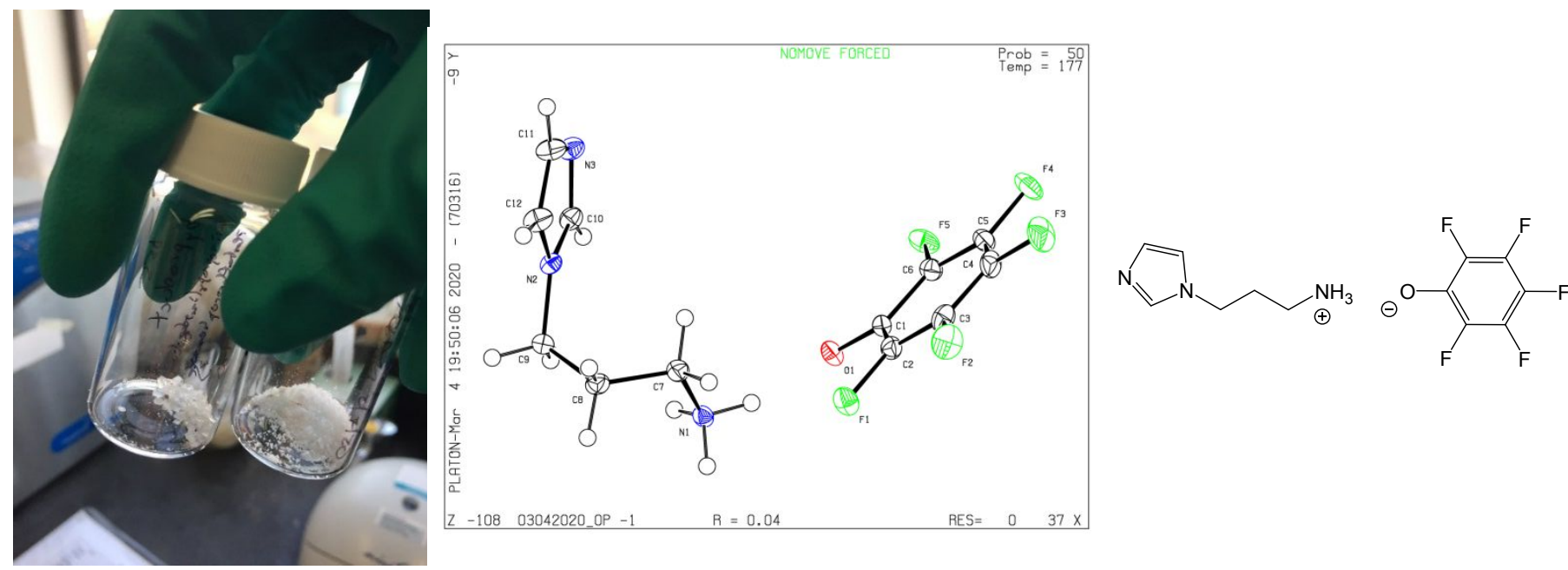

Figure S12. Photograph, crystal structure, and chemical structure of 3-(imidazol-1yl)propylammonium pentafluorophenoxide byproduct. 


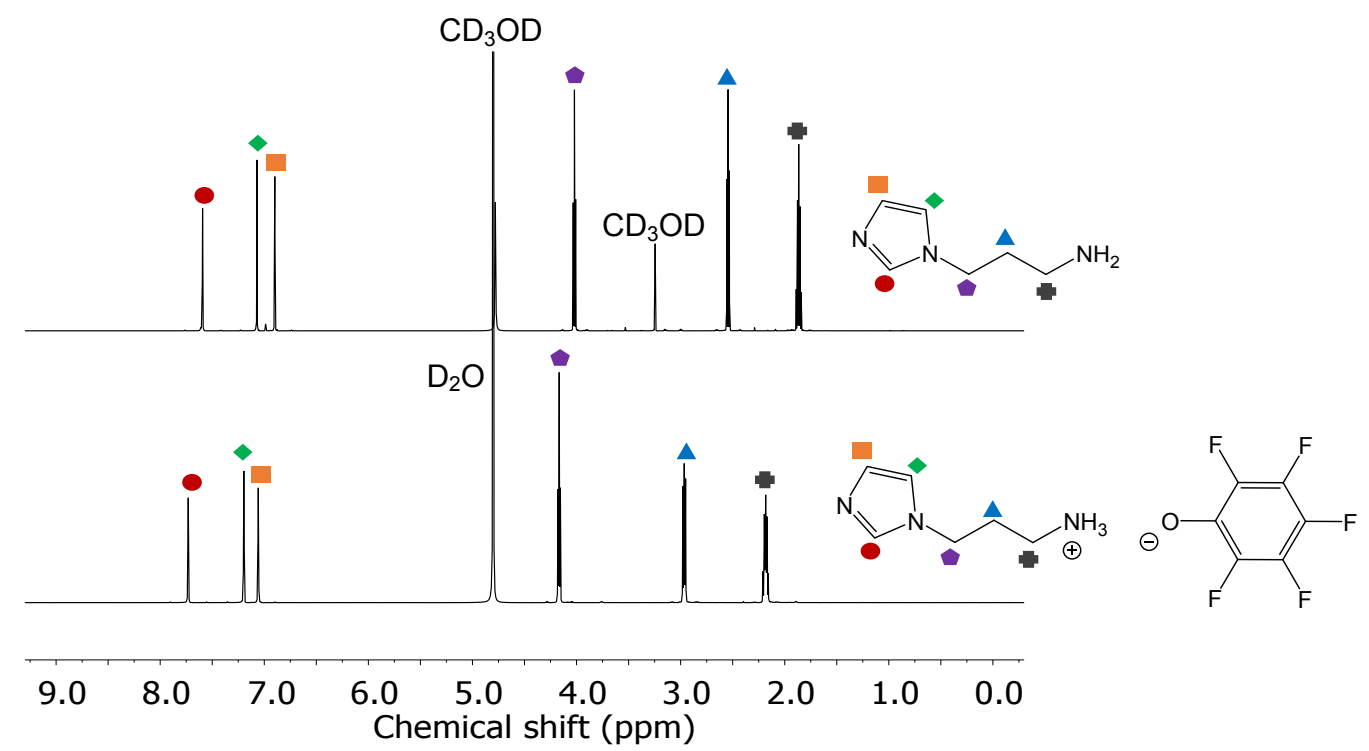

Figure S13. ${ }^{1} \mathrm{H}$ solution NMR of 1-(3-aminopropyl)imidazole in MeOD (top) and 3-(imidazol-1yl)propylammonium pentafluorophenoxide byproduct in $\mathrm{D}_{2} \mathrm{O}$ (bottom).

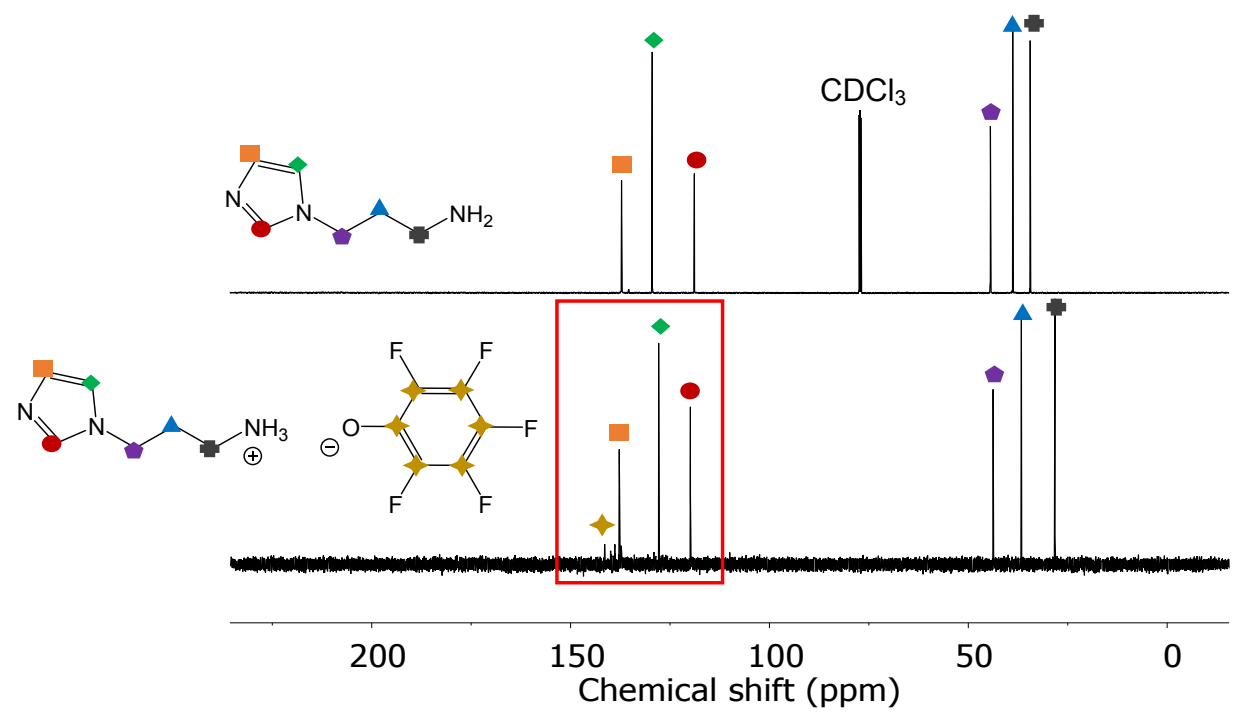

Figure S14. ${ }^{13} \mathrm{C}$ solution NMR of 1-(3-aminopropyl)imidazole in $\mathrm{CDCl}_{3}$ (top) and 3-(imidazol1-yl)propylammonium pentafluorophenoxide byproduct in $\mathrm{D}_{2} \mathrm{O}$ (bottom). 


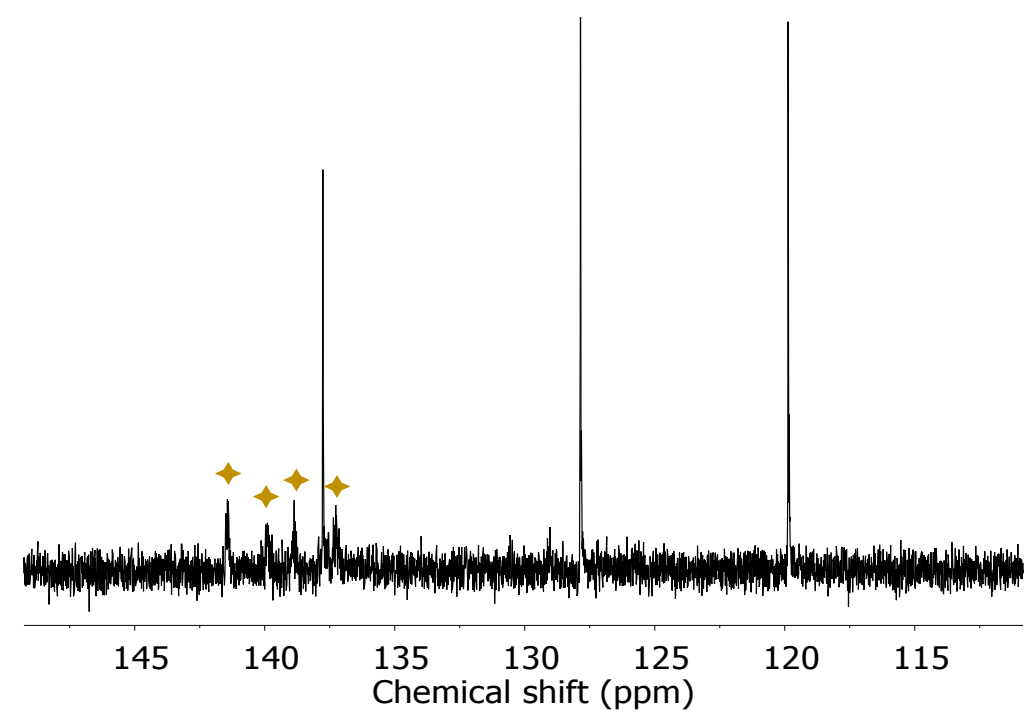

Figure S15. Highlighted region in Figure S14.

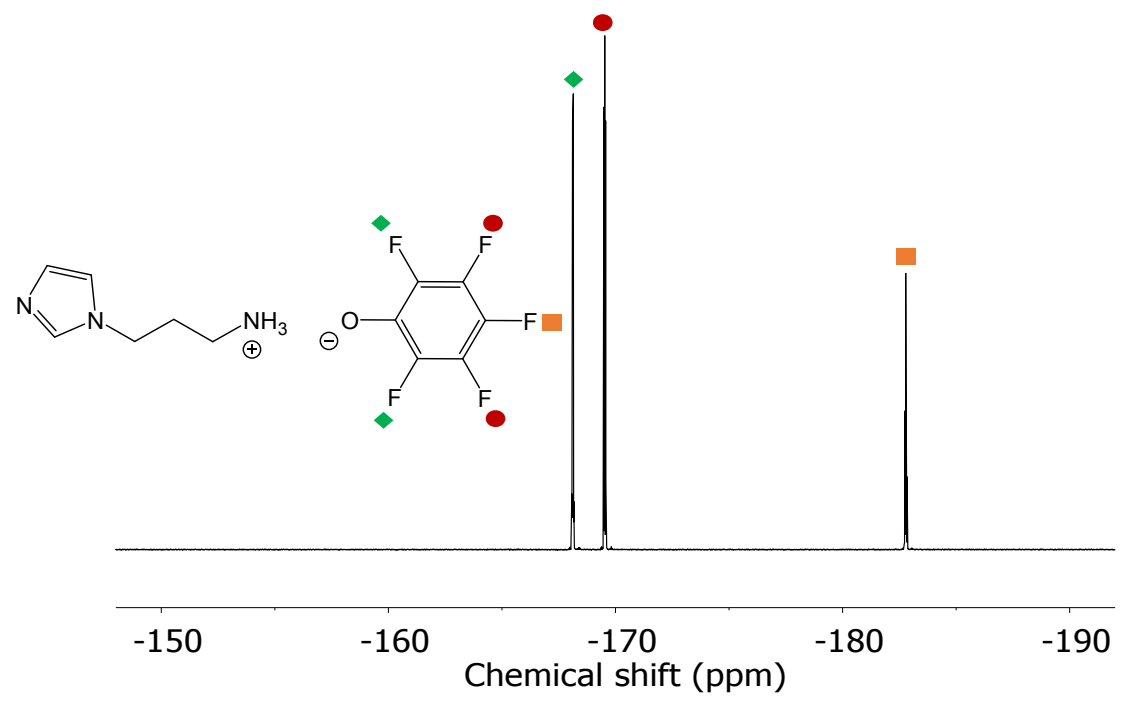

Figure S16. ${ }^{19} \mathrm{~F}$ solution NMR of 3-(imidazol-1-yl)propylammonium pentafluorophenoxide byproduct in $\mathrm{D}_{2} \mathrm{O}$.

\section{Post-polymerization modification of PFPA networks with same crosslinking density but variable PFPA content}

Crosslinked PEGDA/PEGMEA/PFPA random copolymer films containing different ratios of PEGMEA and PFPA were synthesized by free radical polymerization as discussed in section 3. The molarity (and volume fraction) of PEGDA crosslinker was kept constant at $\sim 0.79 \mathrm{M}$ while the fractions of PEGMEA and PFPA monomer were varied. Monomer volume fractions were estimated using density values of $1.12,1.09$, and $1.45 \mathrm{~g} / \mathrm{cm}^{3}$ for PEGDA, PEGMEA, and PFPA, respectively. Monomer compositions are summarized in Table 1. Gel fractions of unsubstituted samples were determined by weighing samples then dialyzing (soaking) in THF for a few days, which was exchanged twice, before drying at $50{ }^{\circ} \mathrm{C}$ under full 
vacuum overnight. Dry samples were weighed again, and gel fraction was determined as the ratio of dry mass after and before THF dialysis. Gel fractions for all samples were 96-98\%. Dried samples were then used for FTIR analysis (Figure S17).

$5 \mathrm{wt} \%$ solutions of 10 eq. (relative to PFPA) 1-(3-aminopropyl)imidazole purified over basic alumina were prepared in THF. Films of each crosslinked network composition were soaked in reaction solutions for 24 hours at room temperature. Polymer films were removed from reaction mixtures and soaked in $10 \mathrm{x}$ excess $0.1 \mathrm{M}$ aqueous $\mathrm{HCl}$ for 24 hours to dissolve any residual byproducts. Films were then transferred to $10 \mathrm{x}$ excess $0.1 \mathrm{M}$ triethylamine to deprotonate imidazoles. Finally, samples were soaked in deionized water for several days, which was exchanged multiple times until $\mathrm{pH}$ remained near neutral. Samples at the highest imidazole grafting density (ImPA-2.7) tended to fracture from swelling when transferred from amine/THF solution to aqueous $\mathrm{HCl}$. This behavior could be mitigated by transferring first to a 70:30 mixture of THF:aqueous $\mathrm{HCl}$, then 30:70 THF: $\mathrm{HCl}$, then finally pure deionized water. Samples were kept in deionized water prior to ion sorption and transport characterization. Samples used in FTIR analysis (Figure S18) were dried at room temperature under full vacuum overnight prior to measurement, and samples subjected to elemental analysis were dried at $50{ }^{\circ} \mathrm{C}$ for 12 hours.

An additional sub-stoichiometric reaction was performed where a 28/20/52 mol\% PEGDA/PEGMEA/PFPA random copolymer film was immersed in a solution of 0.5 eq. (relative to PFPA) 1-(3-aminopropyl)imidazole in THF. This sample was purified using $0.1 \mathrm{M} \mathrm{HCl}, 0.1 \mathrm{M}$ triethylamine, and deionized water as described above and was dried at $50{ }^{\circ} \mathrm{C}$ under full vacuum overnight prior to FTIR analysis (Figure S19) and at $50{ }^{\circ} \mathrm{C}$ for 12 hours prior to elemental analysis. 


\section{a. FTIR analysis}

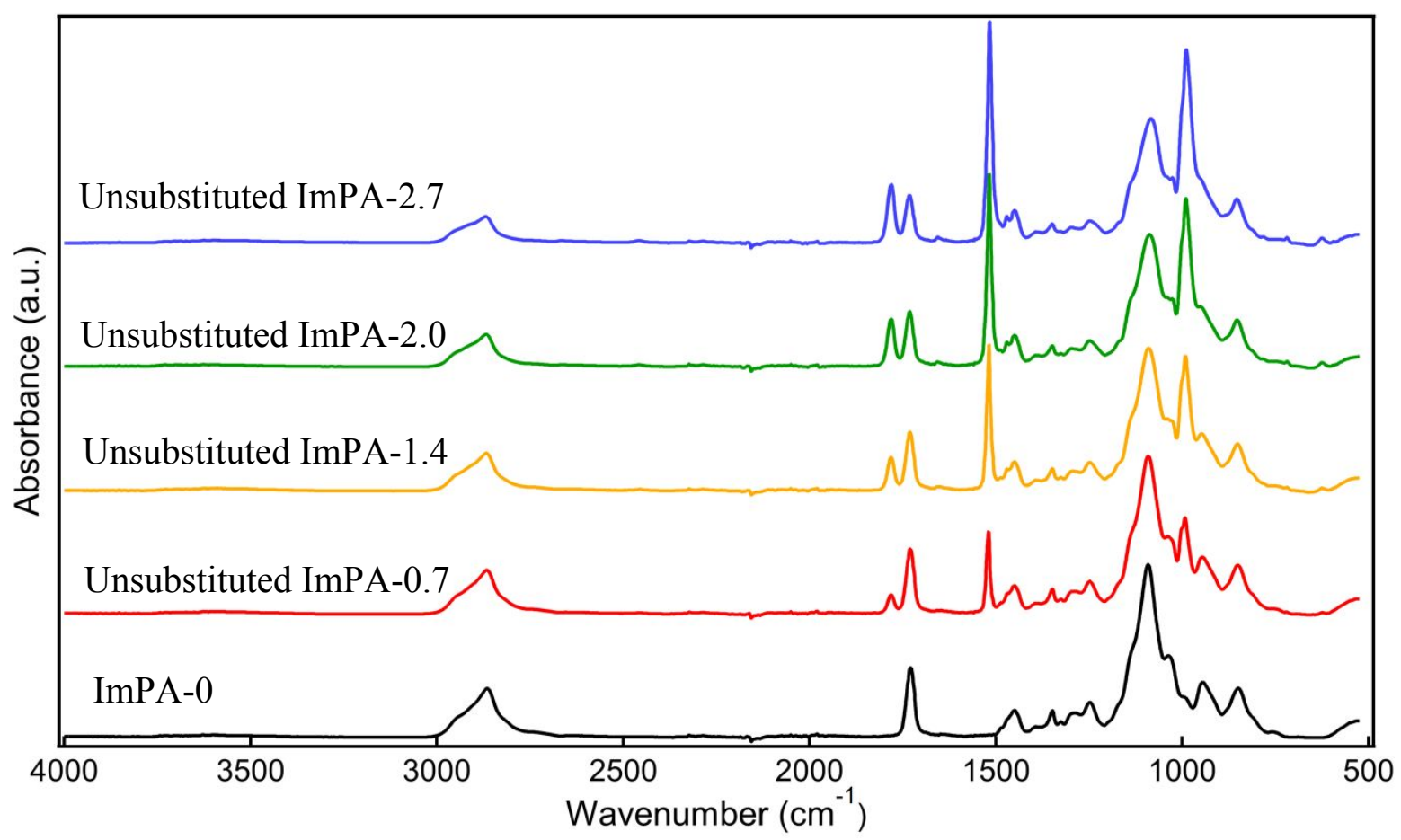

Figure S17. FTIR-ATR spectrograms of unsubstituted PEGDA/PEGMEA/PFPA random copolymer networks. From top to bottom: 21/0/79 mol\% PEGDA/PEGMEA/PFPA (Unsubstituted ImPA-2.7), 24/9/67 mol\% PEGDA/PEGMEA/PFPA (Unsubstituted ImPA-2.0), 28/20/52 mol\% PEGDA/PEGMEA/PFPA (Unsubstituted ImPA-1.4), 33/36/31 mol\% PEGDA/PEGMEA/PFPA (Unsubstituted ImPA-0.7), 41/59/0 mol\% PEGDA/PEGMEA/PFPA (ImPA-0). 


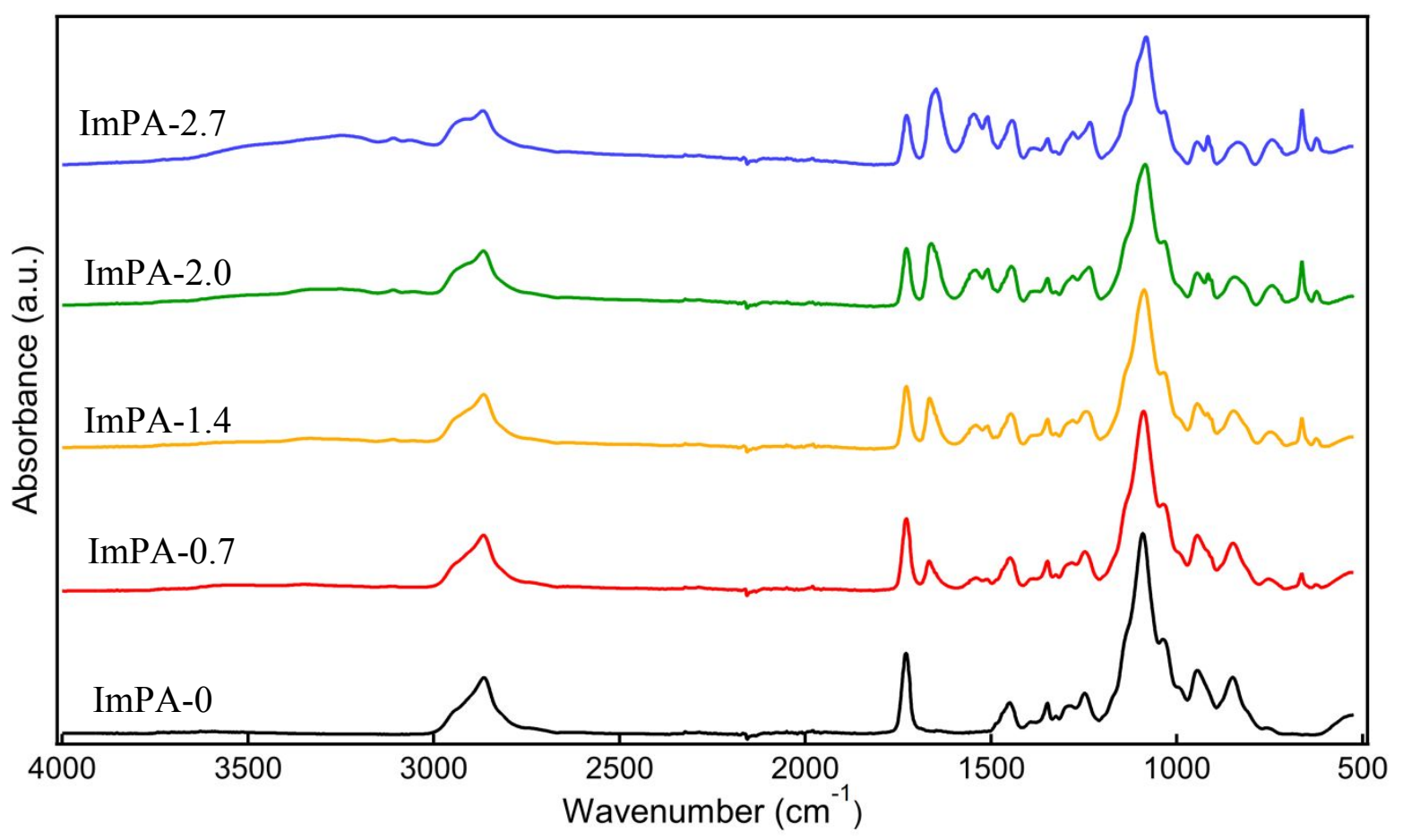

Figure S18. FTIR-ATR spectrograms of imidazole-substituted PEGDA/PEGMEA/ImPA (ImPA =3-(imidazol-1-yl)propylacrylamide) random copolymer networks. From top to bottom: 21/0/79 mol\% PEGDA/PEGMEA/ImPA (ImPA-2.7), 24/9/67 mol\% PEGDA/PEGMEA/ImPA (ImPA-2.0), 28/20/52 mol\% PEGDA/PEGMEA/ImPA (ImPA-1.4), 33/36/31 mol\% PEGDA/PEGMEA/ImPA (ImPA-0.7), 41/59/0 mol\% PEGDA/PEGMEA/ImPA (ImPA-0). 


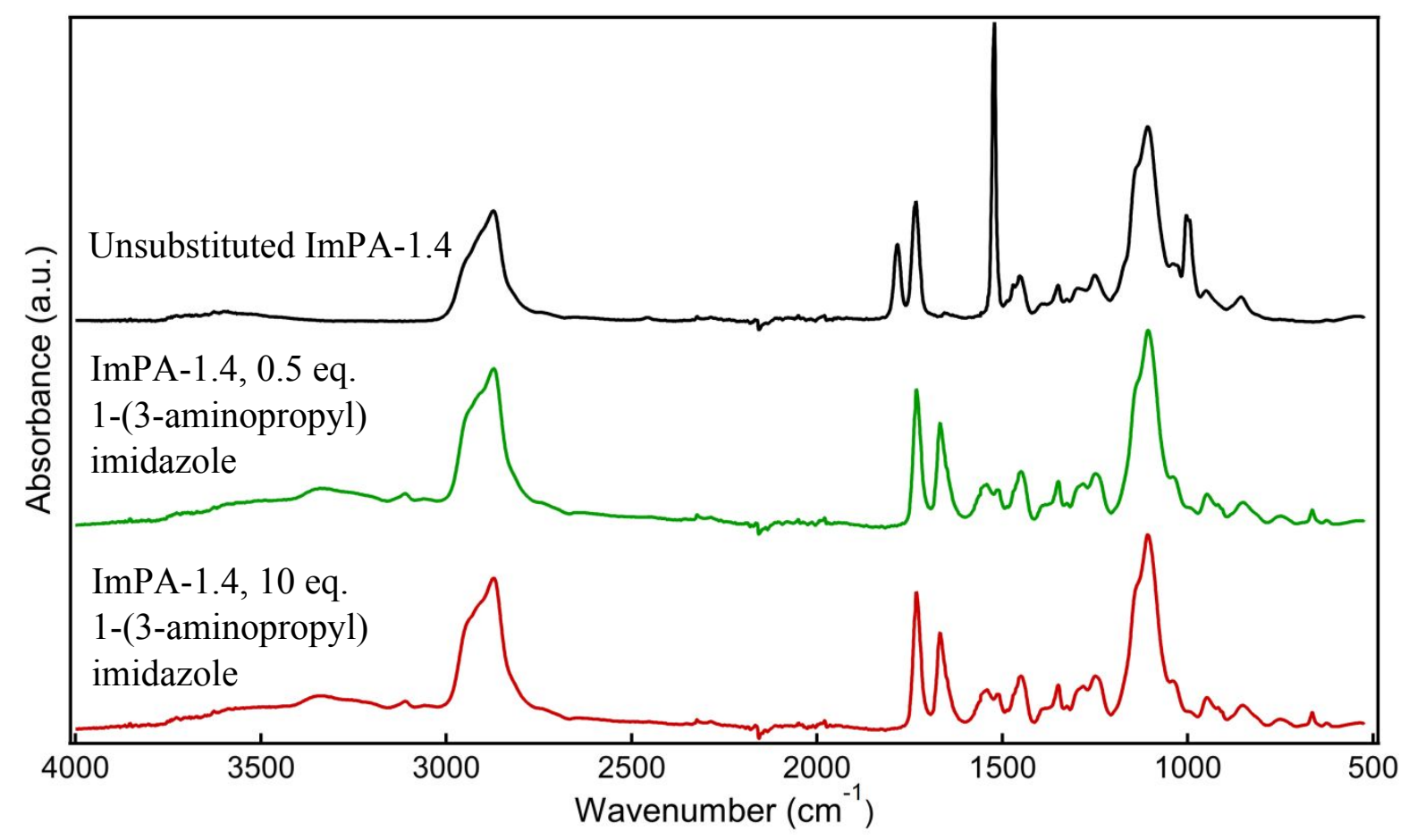

Figure S19. FTIR-ATR spectrograms of unsubstituted and substituted 28/20/52 mol\% PEGDA/PEGMEA/PFPA random copolymer networks. From top to bottom: unsubstituted copolymer network, product after reaction with 0.5 eq. 1-(3-aminopropyl)imidazole in THF, and product after reaction with 10 eq. 1-(3-aminopropyl)imidazole in THF.

Unsubstituted PFPA-containing networks exhibited characteristic stretching bands at $1780 \mathrm{~cm}^{-1}(\mathrm{C}=\mathrm{O}), 1520 \mathrm{~cm}^{-1}(\mathrm{C}=\mathrm{C})$, and $985 \mathrm{~cm}^{-1}(\mathrm{C}-\mathrm{F})$, which increased in intensity proportional to PFPA monomer content (cf., Figure S17). These bands were notably absent after reaction with 10 eq. 1-(3-aminopropyl)imidazole in THF and were replaced by a characteristic amide peak around $1670 \mathrm{~cm}^{-1}$ which increased in intensity proportional to the content of imidazole-substituted acrylamide monomer (cf., Figure S18). Sub-stoichiometric reaction with only 0.5 eq. of 1-(3-aminopropyl)imidazole yielded a product with an essentially identical FTIR signal to the product of the reaction with 10 eq. amine (cf., Figure S19). The absence of PFPA stretching bands in the sub-stoichiometric reaction product indicates the reaction is rapid and complete in the few micrometers of polymer at the surface of the film probed by FTIR-ATR. Amine substitution in the center of the film is incomplete following the sub-stoichiometric reaction, which can be seen in elemental analysis but not FTIR-ATR. The $400 \mu \mathrm{m}$ films were too thick for FTIR to be performed in transmission mode.

\section{b. Elemental analysis}

Elemental analysis was performed on unsubstituted and imidazole-substituted PEGDA/PEGMEA/PFPA random copolymer networks using the procedure described in section 4C. Analysis was also performed on the sub-stoichiometric reaction of a $28 / 20 / 52 \mathrm{~mol} \%$ PEGDA/PEGMEA/PFPA with 0.5 eq. 1-(3-aminopropyl)imidazole in THF. No fluorine was 
detected in 28/20/52 mol\% and 21/0/79 mol\% PEGDA/PEGMEA/PFPA networks after reaction with 10 eq. 1-(3-aminopropyl)imidazole in THF, and nitrogen content indicated $>98 \%$ conversion to the amide. Interestingly, fluorine was also absent in the product of the substoichiometric reaction with 0.5 eq. 1-(3-aminopropyl)imidazole, indicating any unsubstituted PFPA monomers were likely hydrolyzed at some point during workup. Nitrogen content in the sub-stoichiometric reaction product was slightly higher than expected (3.7 vs. $2.7 \mathrm{wt} \%)$.

Table S2. Theoretical and actual elemental mass percentages determined by elemental analysis for unsubstituted and imidazole-substituted PEGDA/PEGMEA/PFPA random copolymer networks. Oxygen analysis could not be performed for fluorine-containing samples due to interference with fluorine.

\begin{tabular}{|l|l|l|l|l|l|l|l|l|l|l|l|}
\hline & \multicolumn{9}{|c|}{ Theoretical mass \% } & \multicolumn{3}{|l|}{ Actual mass \% } \\
\hline $\begin{array}{l}\text { PEGDA/PEGMEA/ } \\
\begin{array}{l}\text { PFPA monomer } \\
\text { mol\% in starting } \\
\text { material }\end{array}\end{array}$ & $\begin{array}{l}\text { Amine } \\
\text { equiv- } \\
\text { alents }\end{array}$ & $\mathbf{C}$ & $\mathbf{H}$ & $\mathbf{N}$ & $\mathbf{O}$ & $\mathbf{F}$ & $\mathbf{C}$ & $\mathbf{H}$ & $\mathbf{N}$ & $\mathbf{O}$ & F \\
\hline $41 / 59 / 0$ & 0 & 54.9 & 8.6 & 0.0 & 36.5 & 0.0 & 53.7 & 8.2 & 0.0 & 36.5 & 0.3 \\
\hline $28 / 20 / 52$ & 10 & 56.2 & 8.2 & 5.7 & 29.9 & 0.0 & 55.7 & 7.6 & 5.8 & 30.7 & 0.2 \\
\hline $21 / 0 / 79$ & 10 & 57.6 & 7.9 & 11.5 & 23.0 & 0.0 & 57.0 & 7.8 & 11.3 & 23.6 & 0.1 \\
\hline $28 / 20 / 52$ & 0 & 52.1 & 6.4 & 0.0 & 29.7 & 11.9 & 51.4 & 6.4 & 0.0 & N/A & 8.6 \\
\hline $28 / 20 / 52$ & 0.5 & 54.1 & 7.3 & 2.7 & 29.8 & 6.2 & 54.8 & 8.2 & 3.7 & 32.7 & 0.2 \\
\hline
\end{tabular}

\section{Qualitative dye uptake measurements}

$400 \mu \mathrm{m}$ thick films of 28/20/52 mol\% PEGDA/PEGMEA/PFPA random copolymer networks were prepared via free radical polymerization as discussed in section 3, weighing about $1 \mathrm{~g}$ each. 28/20/52 mol\% PEGDA/PEGMEA/PFPA networks each were immersed in one of six solutions at ambient temperatures for 30 hours: (A) THF with no amine as a control, (B) 1\% solution of 5 eq. 1-(3-aminopropyl)imidazole in THF, (C) 1\% solution of 5 eq. 1-(2aminoethyl)piperidine in THF, (D) $2 \%$ aqueous solution of 10 eq. $\beta$-alanine and 15 eq. triethylamine, (E) 2\% aqueous solution of 10 eq. taurine and 15 eq. triethylamine, and (F) 2\% aqueous solution of 5 eq. dopamine hydrochloride and 7.5 eq. triethylamine. Each sample was then soaked in excess $0.1 \mathrm{M} \mathrm{HCl}$ for 16 hours followed by soaking in deionized water for a few days, which was exchanged a couple times. $\mathrm{pH}$ values of the deionized water for each of the six samples after soaking were 4.54, 5.20, 3.47, 3.89, 5.65, 4.88, and 5.98, respectively, as measured by an Orion Versa Star Pro $\mathrm{pH}$ meter. $400 \mu \mathrm{m}$ thick films of 41/59 mol\% PEGDA/PEGMEA random copolymer networks without PFPA were also prepared by free radical polymerization as discussed in section 3 and soaked in water for several days before use.

$0.02 \mathrm{mg} / \mathrm{mL}$ aqueous dye solutions of Bromothymol Blue sodium salt, Methyl Orange, Orange II sodium salt, Rhodamine B, and Fluorescein sodium salt were prepared. $0.02 \mathrm{mg} / \mathrm{mL}$ solutions of Bromophenol Blue and 5(6)-carboxyfluorescein were prepared in a 50/50 mixture of water and isopropanol. $0.02 \mathrm{mg} / \mathrm{mL}$ solutions of Thymol Blue in isopropanol were also prepared. $0.1 \mathrm{M}$ aqueous solutions of copper(II) chloride and iron(III) chloride were prepared. Chemical structures of each organic dye are shown in Figure S20. Methyl Orange is a pH indicating dye that changes from red to yellow in the approximate $\mathrm{pH}$ range 3.1-4.4. Bromophenol Blue, Bromothymol Blue, and Thymol Blue change from yellow to blue in 
approximate $\mathrm{pH}$ ranges of 3.0-4.6, 6.0-7.6, and 8.0-9.6, respectively. Fluorescein and 5(6)carboxyfluorescein are anionic dyes with one or two carboxylate groups, respectively, and Orange II is an anionic dye with a sulfonate group. Methylene Blue is a basic, cationic dye, and Rhodamine $\mathrm{B}$ is an amphoteric dye.

Films of 41/59 mol\% PEGDA/PEGMEA and each of the six films of unsubstituted and substituted 28/20/52 mol\% PEGDA/PEGMEA/PFPA were cut into small 5/8 inch diameter circles using a die punch, which weighed about 20-25 mg each when swollen with solvent. Diecut pieces of each sample composition were soaked in $3.0 \mathrm{~mL}$ of different dye and salt solutions for 24-72 hours. Pieces of each sample were also soaked in $3.0 \mathrm{~mL}$ deionized water as a dye-free and salt-free control. Samples were then removed from solutions, and solutions were transferred to new glass vials before taking images of polymers and their respective solutions. Some solutions containing indicating dyes Bromophenol Blue, Bromothymol Blue, and Thymol blue shifted colors slightly after transferring to clean vials, which may be due to residual impurities in the glassware. Polymer samples after soaking in dye and salt solutions are shown in Figure S21.

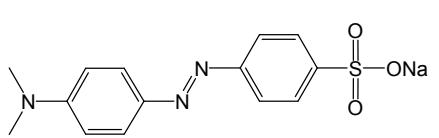

Methyl Orange pH $3.1-4.4$

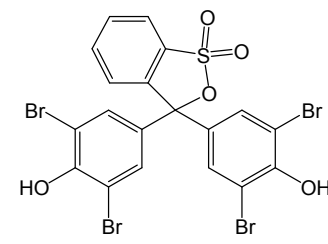

Bromophenol Blue pH $3.0-4.6$

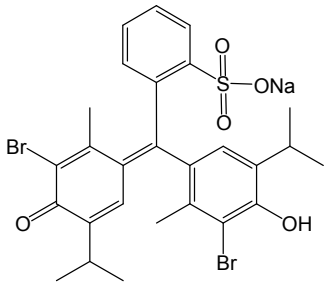

Bromothymol Blue sodium salt pH 6.0 - 7.6

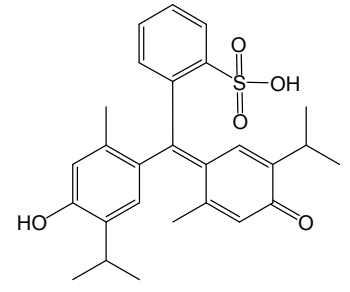

Thymol Blue pH 8.0 - 9.6

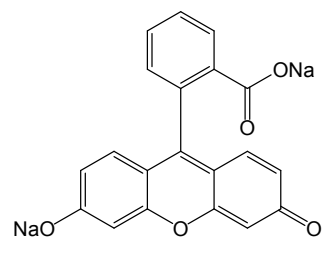

Fluorescein sodium salt

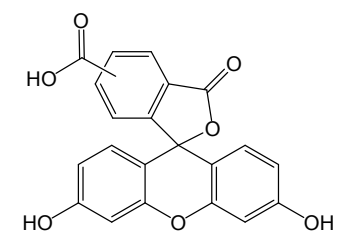

5(6)-carboxyfluorescein

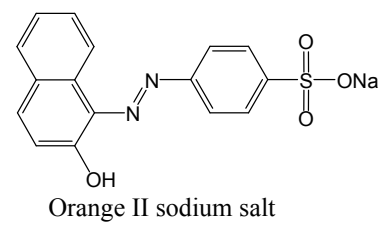

Orange II sodium salt
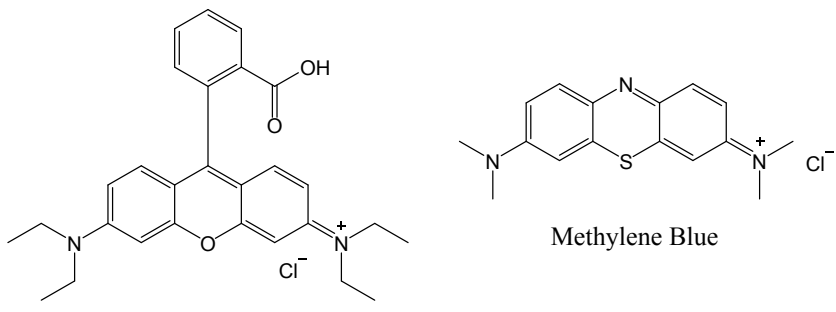

Methylene Blue

Rhodamine B

Figure S20. Chemical structures of organic dyes used for dye uptake measurements. $\mathrm{pH}$ ranges represent approximate ranges over which $\mathrm{pH}$-indicating dyes change color. Only one molecular configuration for each dye is shown based on the structure of the dye as received. 


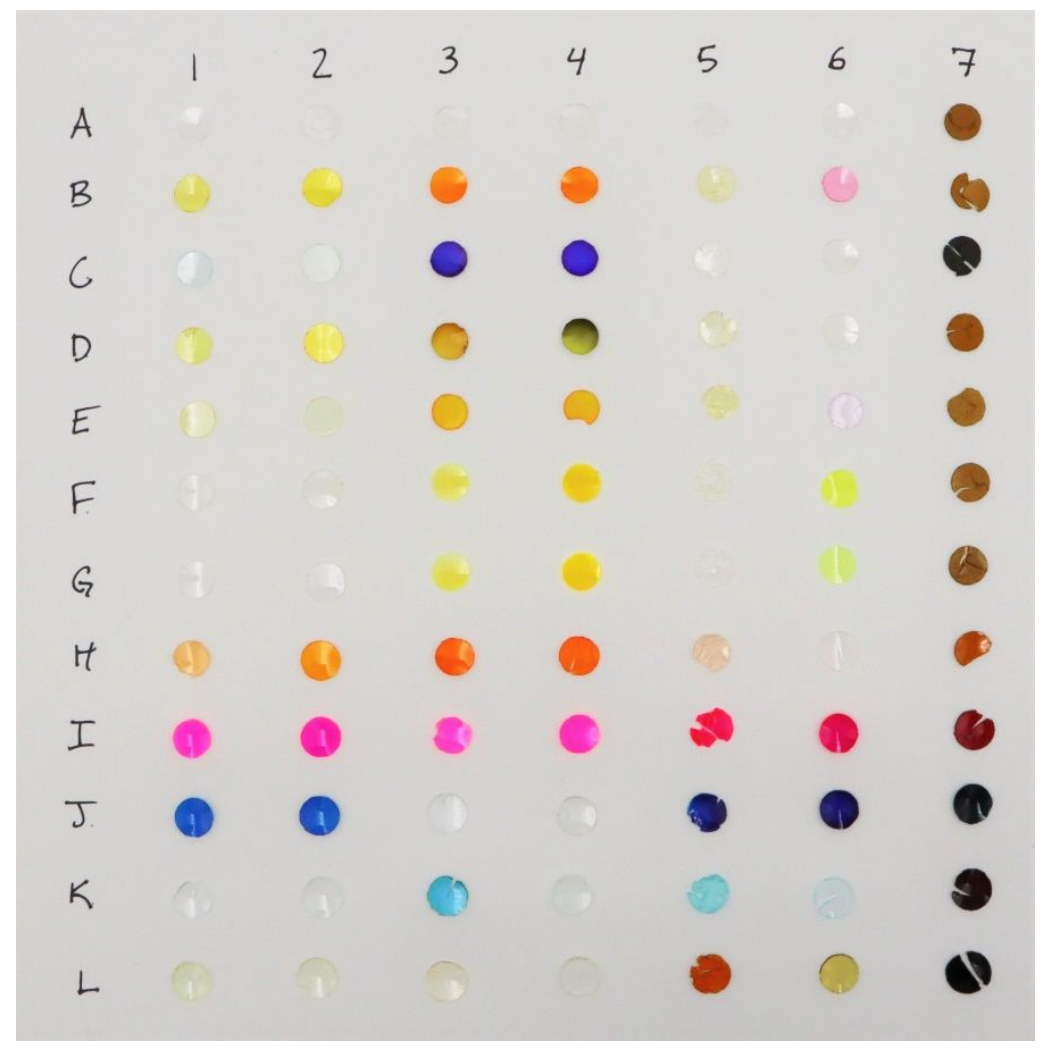

Figure S21. Polymer samples after soaking in $0.02 \mathrm{mg} / \mathrm{mL}$ organic dye or $0.1 \mathrm{M}$ metal chloride salt solutions. Each column corresponds to a different polymer composition: (1) PFPA-free 41/59 mol\% PEGDA/PEGMEA control, (2) unsubstituted 28/20/52 mol\%

PEGDA/PEGMEA/PFPA control, (3) 28/20/52 mol\% PEGDA/PEGMEA/PFPA substituted with 1-(3-aminopropyl)imidazole, (4) 28/20/52 mol\% PEGDA/PEGMEA/PFPA substituted with 1-(2aminoethyl)piperidine, (5) 28/20/52 mol\% PEGDA/PEGMEA/PFPA substituted with $\beta$-alanine, (6) 28/20/52 mol\% PEGDA/PEGMEA/PFPA substituted with taurine, and (7) 28/20/52 mol\% PEGDA/PEGMEA/PFPA substituted with dopamine. Each row corresponds to a different dye or salt solution: (A) deionized water (control), (B) Methyl Orange, (C) Bromophenol Blue, (D) Bromothymol Blue sodium salt, (E) Thymol Blue, (F) Fluorescein sodium salt, (G) 5(6)carboxyfluorescein, (H) Orange II sodium salt, (I) Rhodamine B, (J) Methylene Blue, (K) copper(II) chloride, and (L) iron(III) chloride.

\section{Water uptake and swelling characterization}

Polymer water uptake was measured by soaking samples in DI water for a few days, weighing, then drying at room temperature or $50{ }^{\circ} \mathrm{C}$ under full vacuum overnight and weighing again. Water uptake is defined as:

$$
\% \text { uptake }=\frac{\mathrm{m}_{\mathrm{wet}}-\mathrm{m}_{\mathrm{dry}}}{\mathrm{m}_{\mathrm{dry}}} \times 100 \%
$$

where $\mathrm{m}_{\text {wet }}$ is the sample mass after soaking in DI water, and $\mathrm{m}_{\mathrm{dry}}$ is the dry sample mass. Volumetric swelling was determined by soaking samples in DI water for a few days then 
scanning the surface area of the thin film samples using a digital scanner. Samples were dried at room temperature or $50^{\circ} \mathrm{C}$ under full vacuum overnight and scanned again when dry.

Volumetric swelling was estimated using the following equation assuming isotropic swelling: ${ }^{1}$

$$
\frac{\Delta \mathrm{V}}{\mathrm{V}_{\text {dry }}}=\left(\frac{\mathrm{A}_{\text {swollen }}}{\mathrm{A}_{\text {dry }}}\right)^{3 / 2}-1
$$

where $A_{\text {swollen }}$ is the surface area of the water-swollen film, and $A_{\text {dry }}$ is the surface area of the dry film. Water volume fractions were estimated as:

$$
\phi_{\mathrm{w}}=\frac{\Delta \mathrm{V} / \mathrm{V}_{\mathrm{dry}}}{1+\Delta \mathrm{V} / \mathrm{V}_{\mathrm{dry}}}
$$

\section{Polymer dry density measurement}

Dry polymer densities, $\rho_{\mathrm{p}}$, were determined using an Archimedes density kit and an analytical balance at ambient conditions and were calculated as follows:

$$
\rho_{\mathrm{p}}=\frac{\mathrm{m}_{\mathrm{dry}}}{\mathrm{m}_{\mathrm{dry}}-\mathrm{m}_{\mathrm{sol}}} \rho_{\text {sol }}
$$

where $m_{d r y}$ is the dry mass of the polymer in air, $m_{\text {sol }}$ is the mass of the polymer submerged in a reference solvent, and $\rho_{\text {sol }}$ is the density of the reference solvent at ambient conditions. A hydrophobic and non-polar reference solvent, $n$-heptane, was selected as the polymers are not expected to have affinity for alkanes and solvent uptake should be negligible during measurement. $^{2}$

\section{Salt permeability measurement}

Salt permeabilities were measured using a diaphragm diffusion cell. ${ }^{3-5}$ A polymer film swollen with deionized water was clamped between a plastic donor (or feed) chamber and receiver (or permeate) chamber. The thickness of the swollen sample was previously determined by placing films between two 40-50 $\mu \mathrm{m}$ metal feeler gauges and gently measuring the thickness of the sandwiched sample using a digital Mitutoyo micrometer with \pm 1 micrometer resolution. Feeler gauge thicknesses were subtracted to yield sample thickness. $50 \mathrm{~mL}$ of the desired salt solution of known concentration was added to the donor chamber, and $40 \pm 0.2 \mathrm{~mL}$ of deionized water $(<1.5 \mu \mathrm{S} / \mathrm{cm})$ was added to the receiver chamber. The DI water was equilibrated with air for multiple days to ensure it had reached equilibrium $\mathrm{CO}_{2}$ uptake prior to performing measurements to minimize conductivity drifts due to transient $\mathrm{CO}_{2}$ absorption. Both cells were stirred using small magnetic stir bars, and the tops of the cells were covered with parafilm to minimize water evaporation during the test. Water was circulated around each cell to maintain a uniform temperature of $25 \pm 1{ }^{\circ} \mathrm{C}$ during each test.

The conductivity of the donor chamber was recorded in 5 or 30 second intervals using Thermo Scientific Orion Star A212 and Versa Star Pro conductivity meters. Solution conductivities were converted to salt concentration using calibration curves. Since calibration 
curves were generated at around $18{ }^{\circ} \mathrm{C}$, measured conductivities were normalized to effective conductivities at $18{ }^{\circ} \mathrm{C}$ by multiplying by a small temperature-correction factor provided by the manufacturer of the conductivity meters. The effective membrane sample area was $1.342 \mathrm{~cm}^{2}$. Measurement was allowed to continue until steady-state permeation was reached. Salt permeabilities, $\mathrm{P}_{\mathrm{S}}$, were determined from the slope of concentration vs. temperature in the linear steady-state region:

$$
\mathrm{P}_{\mathrm{s}}=\frac{\mathrm{N}_{\mathrm{A}}}{\mathrm{C}_{\mathrm{s} 0} l}=\frac{\mathrm{dC}_{\mathrm{sl}}(\mathrm{t}) \mathrm{V}}{\mathrm{dt} \quad \mathrm{AC}_{\mathrm{s} 0} l}
$$

where $\mathrm{P}_{\mathrm{s}}$ is salt permeability $\left(\mathrm{cm}^{2} / \mathrm{s}\right), \mathrm{N}_{\mathrm{A}}$ is salt flux (mol salt $\left./ \mathrm{s} \cdot \mathrm{cm}^{2}\right), \mathrm{C}_{\mathrm{s} 0}$ is donor chamber salt concentration ( $\left.\mathrm{mol} \mathrm{salt} / \mathrm{cm}^{3}\right), l$ is polymer film thickness $(\mathrm{cm}), \mathrm{C}_{\mathrm{sl}}$ is receiver chamber salt concentration at time $t\left(\mathrm{~mol} \mathrm{salt} / \mathrm{cm}^{3}\right)$, $\mathrm{t}$ is time $(\mathrm{s}), \mathrm{V}$ is donor chamber volume $\left(\mathrm{cm}^{3}\right)$, and $\mathrm{A}$ is effective membrane sample area $\left(\mathrm{cm}^{2}\right)$. The effect of water counter-diffusion was assumed to be negligible.

\section{Salt sorption measurement}

Previously developed sorption procedures were used to measure equilibrium polymer phase concentrations of $\mathrm{NaCl}, \mathrm{LiCl}, \mathrm{MgCl}_{2}$, and $\mathrm{CuCl}_{2} \cdot{ }^{6-7}$ Samples were subjected to a series of equilibration steps at ambient conditions (i.e., 22-24 ${ }^{\circ} \mathrm{C}$ ) to sorb and desorb salt. Each equilibration step involved soaking polymer samples in a solution of interest for at least 24 hours with periodic replacement of the solution. Initially, samples were equilibrated in ultrapure DI water $(18.2 \mathrm{M} \Omega-\mathrm{cm})$ to remove residual impurities present in the polymer and the waterequilibrated wet mass was recorded. Polymer samples were subsequently equilibrated in $100 \mathrm{~mL}$ of either $0.5 \mathrm{M} \mathrm{NaCl}, \mathrm{LiCl}$, and $\mathrm{MgCl}_{2}$ or $0.1 \mathrm{M} \mathrm{CuCl}_{2}$ and the salt-equilibrated wet mass was recorded. Sorbed salt was then extracted from the polymer by equilibrating each sample in either 100 or $200 \mathrm{~mL}$ of DI water. Cation concentrations in these extraction solutions were determined via inductively coupled plasma optical emission spectrometry (ICP-OES, Agilent Technologies 710-ES) or flame atomic absorbance (Flame AA) spectrometry (Agilent Technologies Varian 240FS AA). Similarly, chloride concentrations in the extraction solutions were determined using an anion exchange ion chromatograph (IC, Dionex Corp. ICS-2100 and IonPac AS18 4 mm column). To ensure complete extraction of mobile salt from the polymer, samples were then subjected to a second DI water extraction step. The second extraction solution was found to contain a negligible amount of ions, so a single desorption step was sufficient extract virtually all mobile ions and is consistent with other studies of ion sorption in polymers. ${ }^{8-9}$ as: ${ }^{3,10-11}$

Salt sorption (or partition) coefficients, $\mathrm{K}_{\mathrm{s}}$, were determined from ICP-OES and IC data

$$
\mathrm{K}_{\mathrm{s}}=\frac{\mathrm{C}_{\mathrm{s}}^{\mathrm{m}, \mathrm{p}}}{\mathrm{C}_{\mathrm{s}}^{\mathrm{s}}}=\frac{\mathrm{c}_{\mathrm{d}} \mathrm{V}_{\mathrm{d}}}{\mathrm{C}_{\mathrm{s}}^{\mathrm{s}} \mathrm{v}_{\mathrm{i}} \mathrm{V}_{\mathrm{p}}}
$$

where $C_{s}^{m, p}$ is salt concentration in the swollen polymer (mol salt $/ \mathrm{cm}^{3}$ swollen polymer), $C_{s}^{s}$ is salt concentration in initial uptake solution ( $\mathrm{mol} \mathrm{salt} / \mathrm{cm}^{3}$ solution), $\mathrm{c}_{\mathrm{d}}$ is the analyte ion 
concentration in the desorption solution at equilibrium ( $\mathrm{mol}$ ion $/ \mathrm{cm}^{3}$ solution), $\mathrm{V}_{\mathrm{d}}$ is volume of desorption solution $\left(\mathrm{cm}^{3}\right), v_{\mathrm{i}}$ is the stoichiometric coefficient of the analyte ion in the salt, and $\mathrm{V}_{\mathrm{p}}$ is volume of the swollen polymer $\left(\mathrm{cm}^{3}\right.$ swollen polymer; i.e., total volume including polymer, water, and salt). The total volume of the swollen polymer was determined as:

$$
\mathrm{V}_{\mathrm{p}}=\hat{\mathrm{V}}_{\mathrm{w}} \mathrm{m}_{\mathrm{p}} \mathrm{w}_{\mathrm{w}}=\frac{\hat{\mathrm{V}}_{\mathrm{w}} \mathrm{m}_{\mathrm{p}} \mathrm{M}_{\mathrm{w}}}{1+\mathrm{M}_{\mathrm{w}}}
$$

where $\hat{V}_{w}$ is the specific volume of sorbed water in the polymer $\left(\mathrm{cm}^{3}\right.$ water/g water), $\mathrm{m}_{\mathrm{p}}$ is mass of the water-swollen polymer $(\mathrm{g}), \mathrm{w}_{\mathrm{w}}$ is water weight fraction in the polymer, and $\mathrm{M}_{\mathrm{w}}$ is experimentally-determined water mass uptake in the polymer ( $g$ water/g dry polymer). The specific volume of sorbed water was further estimated from experimental water uptake and swelling data and polymer density measurements:

$$
\hat{\mathrm{V}}_{\mathrm{w}}=\frac{\Delta \mathrm{V} / \mathrm{V}_{\mathrm{dry}}}{\rho_{\mathrm{p}} \mathrm{M}_{\mathrm{w}}}
$$

where $\rho_{\mathrm{p}}$ is experimentally-measured dry polymer density $\left(\mathrm{g} / \mathrm{cm}^{3}\right)$. Calculated values of $\hat{V}_{\mathrm{w}}$ for all samples were between 1.00 and $1.05 \mathrm{~cm}^{3} / \mathrm{g}$, consistent with the typical assumption of volume additivity. ${ }^{10,12}$ For sample ImPA-2.7, a specific volume of sorbed water of $1.00 \mathrm{~cm}^{3} / \mathrm{g}$ was assumed. Water uptake and swelling data and derived volumetric properties are summarized in Table S3.

Table S3. Water uptake and swelling data and derived volumetric properties for imidazolecontaining PEGDA/PEGMEA/ImPA random copolymer networks with varying imidazole content. Water uptake and swelling values are reported as the average and standard deviation from three separate measurements. *Specific volume of sorbed water for ImPA-2.7 was assumed to be $1.00 \mathrm{~cm}^{3} / \mathrm{g}$.

\begin{tabular}{cccccc}
\hline Polymer & $\begin{array}{c}\text { Water uptake, } \\
\mathrm{M}_{\mathrm{w}} \\
{[\mathrm{g} / \mathrm{g} \text { dry poly }]}\end{array}$ & $\begin{array}{c}\text { Volumetric } \\
\text { swelling, } \\
\Delta \mathrm{V} / \mathrm{V}_{\mathrm{dry}}[\%]\end{array}$ & $\begin{array}{c}\text { Water volume } \\
\text { fraction, } \\
\phi_{\mathrm{w}}\end{array}$ & $\begin{array}{c}\text { Dry polymer } \\
\text { density, } \\
\rho_{\mathrm{p}}\left[\mathrm{g} / \mathrm{cm}^{3}\right]\end{array}$ & $\begin{array}{c}\text { Specific } \\
\text { volume } \\
\text { sorbed water, } \\
\hat{\mathrm{V}}_{\mathrm{w}}\left(\mathrm{cm}^{3} / \mathrm{g}\right)\end{array}$ \\
\hline ImPA-0 & $0.90 \pm 0.04$ & $103 \pm 1$ & $0.51 \pm 0.01$ & $1.10 \pm 0.01$ & $1.04 \pm 0.05$ \\
ImPA-0.7 & $1.01 \pm 0.01$ & $114 \pm 1$ & $0.53 \pm 0.01$ & $1.12 \pm 0.01$ & $1.00 \pm 0.01$ \\
ImPA-1.4 & $1.02 \pm 0.01$ & $114 \pm 2$ & $0.53 \pm 0.01$ & $1.12 \pm 0.03$ & $1.00 \pm 0.04$ \\
ImPA-2.0 & $0.90 \pm 0.04$ & $108 \pm 1$ & $0.52 \pm 0.01$ & $1.15 \pm 0.01$ & $1.05 \pm 0.05$ \\
ImPA-2.7 & $0.85 \pm 0.01$ & $\mathrm{~N} / \mathrm{A}$ & $0.50 \pm 0.01$ & $1.17 \pm 0.01$ & $*$ \\
\hline
\end{tabular}




\section{References}

1. Moon, J. D.; Galizia, M.; Borjigin, H.; Liu, R.; Riffle, J. S.; Freeman, B. D.; Paul, D. R., Water vapor sorption, diffusion, and dilation in polybenzimidazoles. Macromolecules 2018, 51 (18), 7197-7208.

2. $\quad$ Sagle, A. C.; Ju, H.; Freeman, B. D.; Sharma, M. M., PEG-based hydrogel membrane coatings. Polymer 2009, 50 (3), 756-766.

3. Lonsdale, H. K.; Merten, U.; Riley, R. L., Transport properties of cellulose acetate osmotic membranes. Journal of Applied Polymer Science 1965, 9 (4), 1341-1362.

4. Geise, G. M.; Freeman, B. D.; Paul, D. R., Characterization of a sulfonated pentablock copolymer for desalination applications. Polymer 2010, 51 (24), 5815-5822.

5. Jang, E.-S.; Kamcev, J.; Kobayashi, K.; Yan, N.; Sujanani, R.; Dilenschneider, T. J.; Park, H. B.; Paul, D. R.; Freeman, B. D., Influence of water content on alkali metal chloride transport in cross-linked Poly(ethylene glycol) diacrylate.2. Ion diffusion. Polymer 2020, 192, 122316.

6. Geise, G. M.; Falcon, L. P.; Freeman, B. D.; Paul, D. R., Sodium chloride sorption in sulfonated polymers for membrane applications. Journal of Membrane Science 2012, 423-424, 195-208.

7. Kamcev, J.; Paul, D. R.; Freeman, B. D., Ion activity coefficients in ion exchange polymers: Applicability of Manning's counterion condensation theory. Macromolecules 2015, 48 (21), 8011-8024.

8. Galizia, M.; Benedetti, F. M.; Paul, D. R.; Freeman, B. D., Monovalent and divalent ion sorption in a cation exchange membrane based on cross-linked poly (p-styrene sulfonate-codivinylbenzene). Journal of Membrane Science 2017, 535, 132-142.

9. $\quad$ Pintauro, P. N.; Bennion, D. N., Mass transport of electrolytes in membranes. 2. Determination of sodium chloride equilibrium and transport parameters for Nafion. Industrial \& Engineering Chemistry Fundamentals 1984, 23 (2), 234-243.

10. Jang, E.-S.; Kamcev, J.; Kobayashi, K.; Yan, N.; Sujanani, R.; Dilenschneider, T. J.; Park, H. B.; Paul, D. R.; Freeman, B. D., Influence of water content on alkali metal chloride transport in cross-linked poly(ethylene glycol) diacrylate. 1. Ion sorption. Polymer 2019, 178, 121554.

11. Paul, D. R., Reformulation of the solution-diffusion theory of reverse osmosis. Journal of Membrane Science 2004, 241 (2), 371-386.

12. Geise, G. M.; Paul, D. R.; Freeman, B. D., Fundamental water and salt transport properties of polymeric materials. Progress in Polymer Science 2014, 39 (1), 1-42. 